\title{
Photocatalytic Conversion of Nitric Oxide on Titanium Dioxide: Cryotrapping of Reaction Products for Online Monitoring by Mass Spectrometry
}

Weigang Lu, ${ }^{\dagger}$ Abayomi D. Olaitan, ${ }^{\dagger}$ Matthew R. Brantley, ${ }^{\dagger}$ Behrooz Zekavat, ${ }^{\dagger}$ Deniz A. Erdogan, ${ }^{\dagger}$ Emrah Ozensoy, and Touradj Solouki* ${ }^{\dagger}$

${ }^{\dagger}$ Department of Chemistry and Biochemistry, Baylor University, Waco, Texas 76798, United States

${ }^{\ddagger}$ Department of Chemistry, Bilkent University, 06800 Bilkent, Ankara, Turkey

Supporting Information

ABSTRACT: Details of coupling a catalytic reaction chamber to a liquid nitrogen-cooled cryofocuser/triple quadrupole mass spectrometer for online monitoring of nitric oxide (NO) photocatalytic reaction products are presented. Cryogenic trapping of catalytic reaction products, via cryofocusing prior to mass spectrometry analysis, allows unambiguous characterization of nitrous oxide $\left(\mathrm{N}_{2} \mathrm{O}\right)$ and nitrogen oxide species (i.e., $\mathrm{NO}$ and nitrogen dioxide $\left(\mathrm{NO}_{2}\right)$ ) at low concentrations. Results are presented, indicating that the major photocatalytic reaction product of $\mathrm{NO}$ in the presence of titanium dioxide $\left(\mathrm{TiO}_{2}\right) \mathrm{P} 25$ and pure anatase catalysts when exposed to ultraviolet (UV) light (at a wavelength of 365

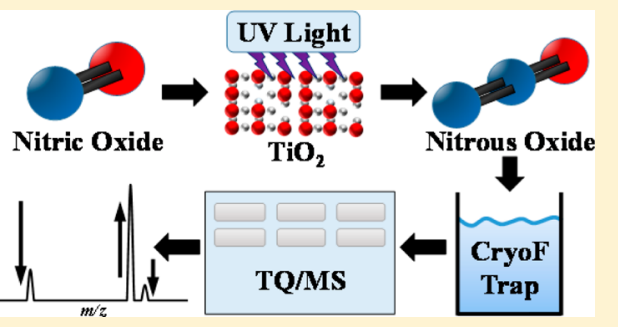
$\mathrm{nm}$ ) is $\mathrm{N}_{2} \mathrm{O}$. However, in the presence of rutile-rich $\mathrm{TiO}_{2}$ catalyst and UV light, the conversion of $\mathrm{NO}_{\text {to }} \mathrm{N}_{2} \mathrm{O}$ was less than $5 \%$ of that observed with the $\mathrm{P} 25$ or pure anatase $\mathrm{TiO}_{2}$ catalysts.

\section{INTRODUCTION}

Photocatalytic processes utilized in the decomposition of organic and inorganic compounds as well as the removal of harmful gases are of great interest in addressing environmental issues associated with air and water pollutants. ${ }^{1,2}$ Nitric oxide (NO) and nitrogen dioxide $\left(\mathrm{NO}_{2}\right)$ are among the major air pollutants originating from fossil fuel combustion in automobile engines and industrial burners. ${ }^{3}$ Various catalytic processes have been developed to convert $\mathrm{NO}_{x}$ gases (i.e., $\mathrm{NO}$ and $\mathrm{NO}_{2}$ ) into nitrogen $\left(\mathrm{N}_{2}\right)$ and oxygen $\left(\mathrm{O}_{2}\right)$ or into nitrates $\left(\mathrm{NO}_{3}{ }^{-}\right)$for $\mathrm{NO}_{x}$ abatement. ${ }^{4-7}$ However, a majority of the catalysts used in converting $\mathrm{NO}_{x}$ gases into harmless gaseous species (i.e., $\mathrm{N}_{2}$ and $\mathrm{O}_{2}$ ) contain expensive precious metals (e.g., $\mathrm{Rh}, \mathrm{Pt}$, or $\mathrm{Pd}$ ) and perform most efficiently at high temperatures $\left(>200^{\circ} \mathrm{C}\right)$. An ideal catalyst for $\mathrm{NO}_{x}$ conversion is expected to convert or store $\mathrm{NO}_{x}$ gases at lower temperatures (e.g., ambient conditions during the cold start of automobile engines).? Titanium dioxide $\left(\mathrm{TiO}_{2}\right)$ is among the major photocatalysts used for catalytic conversion of $\mathrm{NO}_{x}$ gases into nitrous oxide $\left(\mathrm{N}_{2} \mathrm{O}\right)$ and $\mathrm{N}_{2}{ }^{10,11}$ Previous studies have shown promising results where $\mathrm{TiO}_{2}$ catalysts were utilized for $\mathrm{NO}_{x}$ conversion in the presence of solar light. ${ }^{12-17}$

Photocatalytic efficiencies of $\mathrm{TiO}_{2}$ catalysts depend on their crystalline phases, surface morphologies, specific surface areas, electronic structures, and thermal treatments. ${ }^{18,19}$ To achieve peak catalytic performance, optimizations of these parameters are necessary. ${ }^{18,19}$ Most of the previously reported studies on conversion of $\mathrm{NO}_{x}$ gases have employed various spectroscopic (e.g., infrared (IR), ${ }^{20}$ laser absorption, ${ }^{21}$ and chemiluminescence $(\mathrm{CL})^{22}$ ) or electrochemical techniques ${ }^{23}$ for detection of
$\mathrm{NO}_{x}$ reaction products. The use of gas chromatography (GC) systems equipped with electron capture detectors (ECDs) ${ }^{24}$ or mass spectrometers $(\mathrm{MS})^{25,26}$ for identification of $\mathrm{NO}_{x}$ reaction products have been previously reported. In addition, biomedical applications of $\mathrm{NO}$ detection, by using high resolution $\mathrm{MS}^{27}$ and, indirectly, semiconducting metal oxides, ${ }^{28}$ have been reported.

Commercially available $\mathrm{NO}_{x}$ analyzers primarily use either IR or $\mathrm{CL}$ for the detection of $\mathrm{NO}_{x}$ species. ${ }^{22} \mathrm{NO}_{x}$ analyzers based on $\mathrm{CL}$ measurement systems often incorporate a heated molybdenum converter for conversion of $\mathrm{NO}_{2}$ to $\mathrm{NO}$ for subsequent $\mathrm{CL}$ analysis ${ }^{29}$ and are limited to the indirect detection of $\mathrm{NO}_{2}{ }^{22}$ Therefore, conventional CL NO${ }_{x}$ analyzers can only be used for online monitoring of $\mathrm{NO}$ and $\mathrm{NO}_{2}$ during the photocatalytic conversion of $\mathrm{NO}_{x}^{30,31}$ and are not suitable for detection of other potential photocatalytic products such as $\mathrm{N}_{2}$ or $\mathrm{N}_{2} \mathrm{O} .^{10-13,32-35}$ Recently, Bahnemann et al. reported that there may be significant uncertainty in the identity of the detected $\mathrm{NO}_{x}$ species as there could be other nitrogencontaining compounds such as $\mathrm{N}_{2} \mathrm{O}$ which are not detected by $\mathrm{CL}$ analyzers. ${ }^{36,37} \mathrm{~N}_{2} \mathrm{O}$ has previously been reported as a primary photocatalytic decomposition product of $\mathrm{NO}$ using temperature-programmed desorption measurements. ${ }^{13,32,34}$ Also, $\mathrm{N}_{2} \mathrm{O}$ has been shown as a byproduct of $\mathrm{NO}_{x}$ reduction on metal oxides in thermal $\mathrm{DeNO}_{x}$ catalysis. ${ }^{38-41}$

Received: October 30, 2015

Revised: February 2, 2016

Published: February 25, 2016 
MS allows for direct mass-to-charge ratio $(\mathrm{m} / z)$ analysis and hence, it can be used for molecular weight determination of $\mathrm{NO}_{x}$ species and other potential NO photocatalytic products. ${ }^{10-12,14,35,42,43}$ In addition, GC/MS systems provide a higher degree of specificity and selectivity for $\mathrm{NO}_{x}$ separation prior to final analysis. The use of conventional open tubular GC columns for analysis of $\mathrm{NO}_{x}$ gas mixtures is challenging due to poor separation of $\mathrm{NO}$ from $\mathrm{N}_{2}$ and $\mathrm{O}_{2} \cdot{ }^{44}$ To separate $\mathrm{NO}$ from $\mathrm{N}_{2}$ and $\mathrm{O}_{2}$, packed $\mathrm{GC}$ columns made of molecular sieve polymers, such as poly(vinylbenzene), are more suitable. ${ }^{24}$ However, due to the reaction of $\mathrm{NO}_{2}$ with the vinylbenzene molecular sieves, the use of molecular sieve polymers as GC stationary phases hinders the utility of GC for separation and detection of $\mathrm{NO}_{2} .{ }^{7}$ Moreover, $\mathrm{NO}_{x}$ and $\mathrm{N}_{2} \mathrm{O}$ species are often present in the atmosphere at low concentrations (NO: $<1$ $\operatorname{ppb}(\mathrm{v})$ and $\left.\mathrm{N}_{2} \mathrm{O}: \sim 0.32 \operatorname{ppm}(\mathrm{v})\right)^{45}$ which limit the use of conventional GC/MS systems for comprehensive detection of $\mathrm{NO}$ photocatalysis products. Because of the low $\mathrm{NO}_{x}$ and $\mathrm{N}_{2} \mathrm{O}$ concentrations in air, enrichment of pollutants by cryotrapping (cooling with liquid nitrogen) is a useful method for highly sensitive detection of $\mathrm{NO}_{x}$ and $\mathrm{N}_{2} \mathrm{O}$ species. Determination of $\mathrm{NO}_{x}$ and $\mathrm{N}_{2} \mathrm{O}$ concentrations in air has been previously reported using a "cryotrap enrichment" setup coupled to a GC/ MS system. ${ }^{45^{\circ}}$

In this report, we discuss the experimental details of detecting NO and potential NO photocatalytic reaction products using a catalysis unit equipped with mass flow controllers coupled to a liquid nitrogen $\left(\mathrm{LN}_{2}\right)$-cooled cryofocuser/triple quadrupole mass spectrometry (CryoF/ TQMS) system. We utilized the CryoF/TQMS system for direct monitoring of catalytic reaction products from a gas stream sample containing $80 \mathrm{ppm}$ of $\mathrm{NO}$ in simulated air (i.e., diluted in $80 \% \mathrm{~N}_{2}$ and $20 \% \mathrm{O}_{2}$ ) in the presence of $\mathrm{TiO}_{2}$ catalysts and ultraviolet (UV) radiation (wavelength maximum, $\lambda_{\max }=365 \mathrm{~nm}$ ). We show that the CryoF/TQMS approach allows for detection of the photocatalytic reaction products of $\mathrm{NO}$ (e.g., $\mathrm{N}_{2} \mathrm{O}$ as the major product) in the presence of high concentrations of $\mathrm{O}_{2}$ and $\mathrm{N}_{2}$. NO concentrations in the range of 10 and $200 \mathrm{ppm}$ have been previously employed to monitor the photocatalytic conversion of $\mathrm{NO}_{x}$ gases using $\mathrm{TiO}_{2}$ catalysts; $^{1,46,47}$ hence, $80 \mathrm{ppm}$ of $\mathrm{NO}$ concentration (i.e., midrange of previous studies) was utilized to demonstrate the catalytic conversion of $\mathrm{NO}$ using a unique CryoF/TQMS system. Future studies will employ lower NO concentrations (e.g., <1 ppm) for targeting specific applications such as studying the air purification performance of $\mathrm{TiO}_{2}$-based photocatalysts as filters to clean indoor $\mathrm{NO}_{x}$ contaminants. P25 $\mathrm{TiO}_{2}$ catalyst has been shown to have very high photocatalytic activity for the removal of $\mathrm{NO}_{x}$ gases ${ }^{16,48,49}$ and is a benchmark catalyst for studying the photocatalytic decomposition of NO; hence, we also included $\mathrm{P} 25 \mathrm{TiO}_{2}$ in our studies.

\section{EXPERIMENTAL METHODS}

2.1. Sample Preparation. Nitric oxide (NO) (100 ppm balanced with nitrogen $\left(\mathrm{N}_{2}\right)$ ), ultrahigh purity (UHP) oxygen $\left(\mathrm{O}_{2}\right)$ (purity: 99.993\%), UHP $\mathrm{N}_{2}$ (purity: $99.999 \%$ ), and UHP helium (He) (purity: 99.999\%) gases were purchased from a commercial source (Praxair, Danbury, CT). Aeroxide P25 titanium dioxide $\left(\mathrm{TiO}_{2}\right)$ (average particle size: $21 \mathrm{~nm}$, purity: $>99.5 \%$ ) was purchased from Sigma-Aldrich (Sigma-Aldrich, St. Louis, MO). Pure anatase $\mathrm{TiO}_{2}$ (Nanostructured and Amorphous Materials Inc., Houston, TX) and rutile-rich
$\mathrm{TiO}_{2}$ (Skyspring Nanomaterials, Inc., Houston, TX) were provided by Dr. Boris Lau (Baylor University, Waco, TX) and were characterized by X-ray diffraction to confirm anatase/ rutile ratios. Standard nitrous oxide $\left(\mathrm{N}_{2} \mathrm{O}\right)$ (purity: $\left.99.99 \%\right)$ gas sample was purchased from Matheson (Basking Ridge, NJ). The nitrogen dioxide $\left(\mathrm{NO}_{2}\right)$ standard sample was prepared by reacting copper metal with nitric acid. ${ }^{50} 80 \mathrm{ppm}$ of $\mathrm{NO}$ in simulated air $\left(80 \% \mathrm{~N}_{2}\right.$ and $\left.20 \% \mathrm{O}_{2}\right)$ was prepared online by the controlled mixing of $20 \mathrm{sccm}$ (standard cubic centimeter per minute) of $100 \mathrm{ppm}$ of $\mathrm{NO}$ (balanced in $\mathrm{N}_{2}$ ) with $5 \mathrm{sccm}$ of $\mathrm{UHP} \mathrm{O}_{2}$. All other gases (i.e., $\mathrm{N}_{2}, \mathrm{O}_{2}$, and $\mathrm{He}$ ) discussed in this report were used "as-is" and without further refinement. Unless explicitly stated otherwise, the temperature and relative humidity of the catalytic reaction chamber (measured using a humidity sensor (model HTU21D(F), Measurement Specialties, Hampton, VA) placed inside of the catalytic bed) were 23 $\pm 2{ }^{\circ} \mathrm{C}$ and $24 \pm 2 \%$, respectively. During the exposure of the $\mathrm{TiO}_{2}$ catalysts to UV radiation, the temperature of the catalytic reaction chamber increased by $\sim 2{ }^{\circ} \mathrm{C}$.

$\mathrm{TiO}_{2}$ catalysts used in all $\mathrm{NO}$ photocatalytic reactions presented in this article were used as provided (i.e., without initial UV preactivation). However, additional experiments were conducted on the photocatalytic conversion of $\mathrm{NO}$ in the presence of preactivated (i.e., with $15 \mathrm{~h}$ of UV light exposure, $\lambda_{\max }=365 \mathrm{~nm}$ ) P25 and pure anatase $\mathrm{TiO}_{2}$ catalysts (nine experimental trials were performed for each catalyst over a three-day period), but no significant changes to the $\mathrm{NO}, \mathrm{N}_{2} \mathrm{O}$, and $\mathrm{NO}_{2}$ trends (as compared to experiments with the nonactivated P25 and pure anatase $\mathrm{TiO}_{2}$ catalysts) were observed. The cryofocuser and mass spectrometer were used to continuously monitor gases released before, during, and after the exposure of the $\mathrm{TiO}_{2}$ catalyst to UV radiation (i.e., UV pretreatment) and no released contaminants from the catalyst were detected. Hence, the $\mathrm{TiO}_{2}$ catalysts utilized in this report were utilized without any degreening/pretreatment.

2.2. Powder X-ray Diffraction (XRD). Powder X-ray diffraction (XRD) spectra of $\mathrm{TiO}_{2}$ samples were obtained using a Siemens D5000 diffractometer (formerly Siemens-now a division of Bruker Corporation, Billerica, MA) equipped with a $\mathrm{Cu} \mathrm{K} \alpha$ radiation $(\lambda=1.54184 \AA$, generated at $40 \mathrm{kV}$ and 30 $\mathrm{mA}$ ) source and operated in $\theta-2 \theta$ mode. Verification of anatase/rutile ratios for each $\mathrm{TiO}_{2}$ catalyst was calculated using the equation: ${ }^{51}$

$$
x=\left(1+0.8 \frac{I_{\mathrm{A}}}{I_{\mathrm{R}}}\right)^{-1}
$$

where $x$ is the fraction (by weight) of rutile, $I_{\mathrm{A}}$ is the peak intensity for the anatase (101) peak (labeled "A" in Figure 3), and $I_{\mathrm{R}}$ is the peak intensity for the rutile (110) peak (labeled "R" in Figure 3).

2.3. Transmission Electron Microscopy (TEM). Analysis of average particle diameters was performed using transmission electron microscopy (TEM). Briefly, the pure anatase, rutilerich, and $\mathrm{P} 25 \mathrm{TiO}_{2}$ catalysts were suspended in pure ethanol and sonicated for approximately $30 \mathrm{~min}$. Concurrently, FORMVAR 15/95 (Electron Microscopy Sciences, Hatfield, PA) coated copper grids were glow discharged using an EM ACE600 (Leica Microsystems, Wetzlar, Germany) operating at $10 \mathrm{~mA}$ for $10 \mathrm{~s}$ at a working distance of $50 \mathrm{~mm}$. Grids were placed for $5 \mathrm{~min}$ on drops of suspended titania species and airdried. 
TEM analysis was performed using a JEM-1010 (JEOL, Ltd., Tokyo, Japan) operating at $100 \mathrm{kV}$ equipped with an XR16ActiveVu camera (AMT, MA, USA) at $50000 \times$ magnification. Data processing and particle size measurements were performed using the Cell $\mathrm{F}$ software package equipped with the particle analysis toolkit (Olympus, Life and Material Science Europa GmbH, Hamburg, Germany).

2.4. Photocatalysis Unit. The design of the catalysis unit was similar to a previously reported photocatalytic flow reactor system equipped with a chemiluminescence $\mathrm{NO}_{x}$ analyzer. ${ }^{31}$ Briefly, the catalysis unit consisted of a reaction chamber made of poly(methyl methacrylate) (length: $7.0 \mathrm{~cm}$; width: $8.0 \mathrm{~cm}$; height: $5.0 \mathrm{~cm}$ ) transparent thermoplastic material (refer to Scheme 1 for a simplified schematic representation of this unit).

Scheme 1. Simplified Schematic Representation of the Catalysis Unit Coupled to the Cryofocuser/Triple Quadrupole MS System ${ }^{a}$

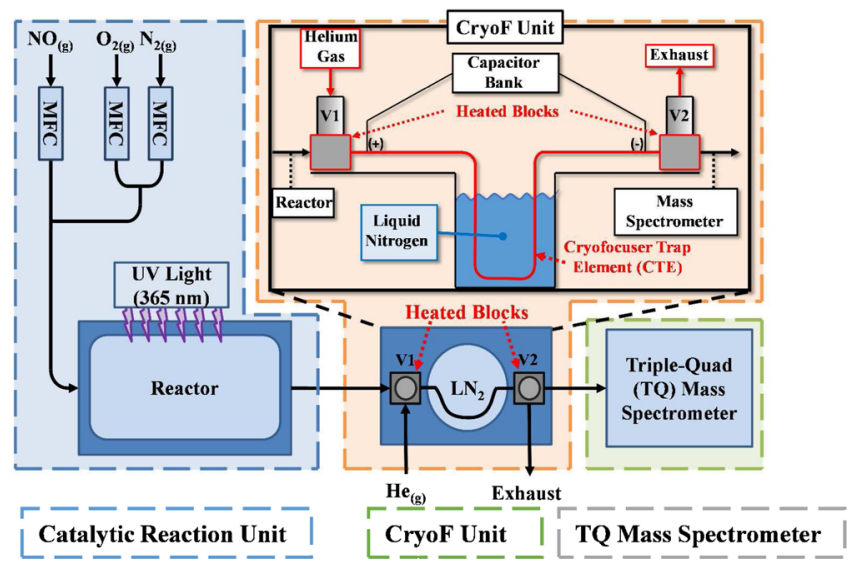

${ }^{a}$ Note: GC is not shown in this scheme, as it was only used for experiments confirming the identity of $\mathrm{N}_{2} \mathrm{O}$.

The reaction chamber was equipped with (i) a catalyst bed (length: $4.0 \mathrm{~cm}$; width: $4.0 \mathrm{~cm}$; height: $0.2 \mathrm{~cm}$ ) and (ii) a quartz window (length: $4.0 \mathrm{~cm}$; width: $4.0 \mathrm{~cm}$; height: $0.2 \mathrm{~cm}$ ). The quartz window was placed on top of the catalyst bed to allow UV radiation from a UV lamp (model UVGL-25, UVP, Upland, $\mathrm{CA}$ ) into the catalyst bed. For the experiments reported herein, the photon power density of the UV lamp positioned over the catalytic bed was $7.2 \mathrm{~W} / \mathrm{m}^{2}$ (peak $\lambda$ at $365 \mathrm{~nm}$ ) per manufacturer's specifications. The reaction chamber was connected to three separate gas inlets via a gas manifold. Each gas inlet was in turn connected to a dedicated gas mass flow controller (MFC) (model GM50A, MKS Instruments Inc., San Jose, CA) for controlled introduction of $\mathrm{N}_{2}, \mathrm{O}_{2}$, and $\mathrm{NO}$ gases into the reaction chamber.

2.5. Cryofocuser (CryoF) Unit. The basic design of the CryoF assembly was similar to the original design of Jacoby et al. $^{53}$ and our previously reported interface for GC/MS. ${ }^{54}$ The CryoF assembly consisted of a capacitive discharge unit for resistive heating of the CryoF trap element (CTE). The CTE was a $10.16 \mathrm{~cm}$ Sulfinert stainless steel tube (inner diameter (i.d.): $0.053 \mathrm{~cm}$; outer diameter (o.d.): $0.074 \mathrm{~cm}$, Restek Corp., Bellefonte, PA) immersed in a Teflon (DuPont, Wilmington, DE) cup capable of holding $100 \mathrm{~mL}$ of liquid nitrogen $\left(\mathrm{LN}_{2}\right)$. The total resistance of the CTE was $1.2 \Omega$. Two parallel pairs of $0.1 \mathrm{~F}$ capacitors (i.e., a total of four capacitors) were connected in series to produce a total capacitance of $0.1 \mathrm{~F}$ in the discharge unit. The capacitors within the discharge unit were electrically charged using an Agilent $500 \mathrm{~W}$ direct current (dc) power supply (model 6554A, Agilent Technologies, Inc., Santa Clara, $\mathrm{CA}$ ). A dc voltage of $40 \mathrm{~V}$ (maximum output current of $4.0 \mathrm{~A}$ ) was used for flash heating of the trap element. Desorption temperatures in excess of $200{ }^{\circ} \mathrm{C}$ (measured with careful calibration of the resistance change of the CTE within the $\mathrm{LN}_{2}$ bath as a function of temperature) could be achieved in the trap element during the flash heating cycle. Two brass heating blocks (length: $2.5 \mathrm{~cm}$; width: $1.8 \mathrm{~cm}$; height: $1.3 \mathrm{~cm}$ ) were used on both ends of the CTE to avoid "cold spots". The entire length of the transfer lines on both sides of the CTE was continuously heated and kept at $150{ }^{\circ} \mathrm{C}$ throughout the experiments.

During the flash heating cycle, the CTE was resistively heated by discharging the capacitors in the discharge unit onto the trap element. The capacitive discharge event was initiated upon receiving a $5 \mathrm{~V}$ logic level signal from the CryoF Unit microcontroller. The CryoF Unit and its associated pulse valves, flash heating cycle, and cryofocusing time were controlled using an in-house developed computer program (written in $\mathrm{C} / \mathrm{C}++$, compiled using avr-g++). ${ }^{55}$ The computer program was loaded onto an Arduino Uno R3 microcontroller (Arduino, Torino, Italy) which subsequently controlled pulse valve actuations and flash heating via digitally controlled relay switches on a Relay4 Board (Microelektronika, Belgrade, Serbia).

For the experiments reported herein, various cooling periods (i.e., cryofocusing times) were utilized and the heating cycle time was held constant at $100 \mathrm{~ms}$. It should be noted that heating time was governed by the time constant $(\tau)$ of the RC circuit used in the discharge unit of the CryoF, which was $\sim 72.8 \mathrm{~ms}$ (hence, a $100 \mathrm{~ms}$ heating cycle time was sufficient to encompass the full discharge period).

2.6. Gas Chromatography (GC). The heated transfer line from pulse valve \#2 (labeled "V2" in Scheme 1) was directly connected to the injection port (kept at $100{ }^{\circ} \mathrm{C}$ ) of a GC system. The GC column was a Porapak Q (length: $183 \mathrm{~cm}$; i.d.: $0.21 \mathrm{~cm}$; particle size: 80/100 mesh) stainless steel packed column (Restek Corp., Bellefonte, PA) housed in an SRI GC instrument (model 8610C, SRI Instruments, Las Vegas, NV). Helium ( $\mathrm{He}$ ) gas was used as the GC carrier gas with the $\mathrm{He}$ head pressure set to $10 \mathrm{psi}$; the GC oven temperature was isothermal at $60^{\circ} \mathrm{C}$. GC effluent was directly sent into the mass spectrometer through a heated transfer line (kept at $150{ }^{\circ} \mathrm{C}$ ). GC was utilized only in experiments aimed at confirming the identity of $\mathrm{N}_{2} \mathrm{O}$ and thus was not included in Scheme 1 .

2.7. Mass Spectrometry (MS). Mass spectra were collected using a triple quadrupole (TQ) mass spectrometer (Model 1200L, formerly Varian Corp.-now a division of Agilent Technologies, Inc., Santa Clara, CA) equipped with an electron ionization (EI) source operated in positive-ion mode. Electron energy was set to $70 \mathrm{eV}$. The TQMS system was operated in scan mode (i.e., Q1 $\rightarrow$ scan, Q2 and Q3 $\rightarrow$ no scan) with $\mathrm{m} / z$ scan range set between 14 and $100 \mathrm{Th}$ (at a rate of $16 \mathrm{scans} / \mathrm{s})$. MS instrument control and data analyses were performed using the Varian Mass Workstation software (version 6.9.1, formerly Varian Corp.--now a division of Agilent Technologies, Inc., Santa Clara, CA). To ensure optimum instrument performance, standard "autotune" and instrument calibrations were performed on a daily basis prior to all MS measurements. Optimized electron multiplier voltages and standard calibration parameters (from the autotune files) 

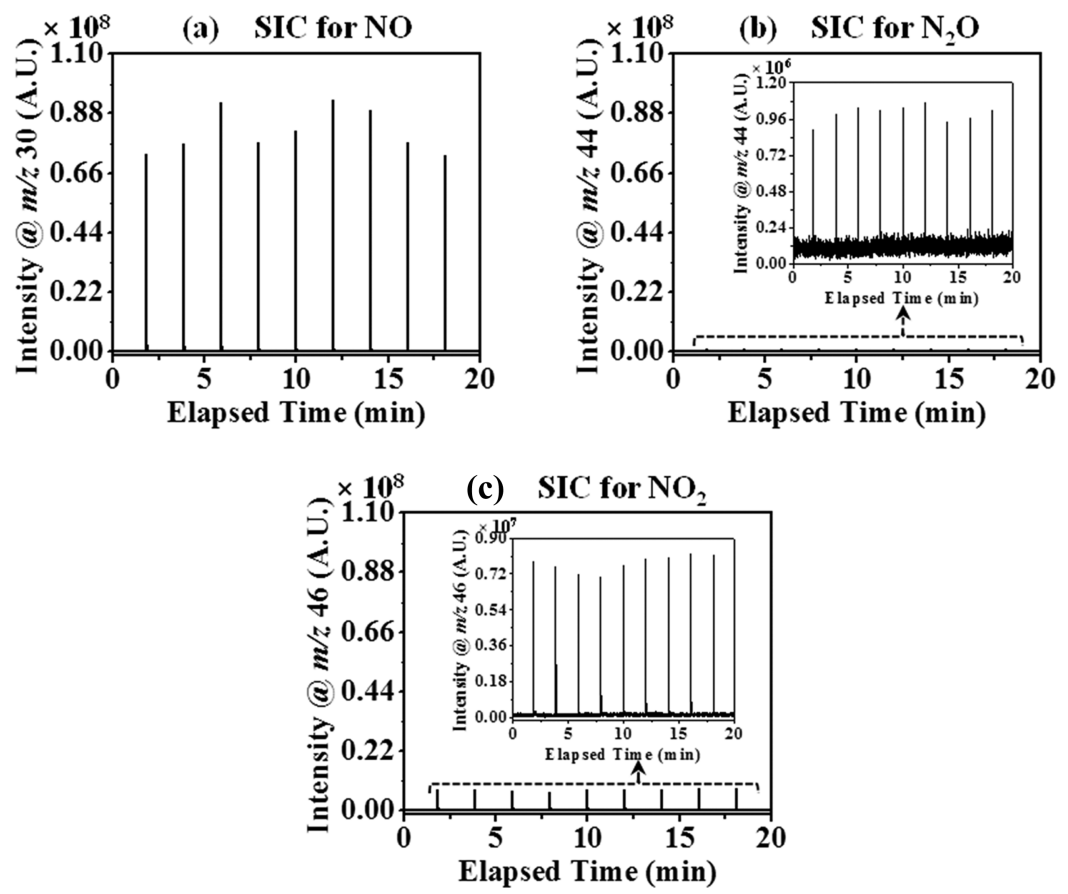

Figure 1. Representative selected ion chromatograms (SICs) for (a) $\mathrm{NO}^{\bullet+}(m / z 30)$, (b) $\mathrm{N}_{2} \mathrm{O}^{\bullet+}\left(\mathrm{m} / z\right.$ 44), and (c) $\mathrm{NO}_{2}{ }^{\bullet+}(m / z 46)$ in the absence of $\mathrm{TiO}_{2}$ catalyst and UV light. $\mathrm{NO}$ concentration was $80 \mathrm{ppm}$ in simulated air. Insets in (b) and (c) show the expanded regions of the $\mathrm{SIC}$ for $\mathrm{N}_{2} \mathrm{O}^{\bullet+}$ $(m / z 44)$ and $\mathrm{NO}_{2}{ }^{++}(m / z 46)$, respectively.

were used for all subsequent data acquisitions. TQ mass spectrometer ion source and transfer line temperatures were set to $150{ }^{\circ} \mathrm{C}$. For experiments performed without the SRI GC connected, TQ mass spectrometer ion source and main vacuum chamber pressures were generally $<2.5 \times 10^{-3}$ and $<6.0 \times 10^{-7}$ Torr, respectively. Instrument, method, and sample blanks were used to identify potential chemical contaminants for background correction. The ion intensities (i.e., peak areas) for the $\mathrm{NO}, \mathrm{N}_{2} \mathrm{O}$, and $\mathrm{NO}_{2}$ species represented in Figures 1, 2, and 4 were corrected for ionization sensitivity (IS). Previously reported literature values of $\mathrm{NO}$ (i.e., 1.17) and $\mathrm{N}_{2} \mathrm{O}$ (i.e., 1.66) were utilized for IS correction. ${ }^{56}$ The IS value of 1.39 for $\mathrm{NO}_{2}$ was calculated based on the relationship between molecular polarizability $(\alpha)$ and IS (i.e., IS $=0.36 \alpha+0.30$ ), ${ }^{57}$ using $\alpha=3.02 \AA^{3}$ for $\mathrm{NO}_{2}{ }^{58}$ Hence, we divided the peak areas of $\mathrm{NO}, \mathrm{N}_{2} \mathrm{O}$, and $\mathrm{NO}_{2}$ by $1.17,1.66$, and 1.39 , respectively, to obtain their corrected peak areas.

\section{RESULTS AND DISCUSSION}

In the following sections, we present results from the use of a cryofocuser (CryoF)/TQ mass spectrometer coupled to a catalytic reaction unit to study nitric oxide (NO) decomposition products in either the absence or presence of $\mathrm{TiO}_{2}$ catalysts with and without UV radiation.

3.1. Catalysis Reaction Unit Coupled to a Cryofocuser/ Triple Quadrupole Mass Spectrometry System. A modular block diagram of the instrumental setup used in this study (for continuous monitoring of the products formed during the photocatalytic conversion of $\mathrm{NO}$ ) is displayed in Scheme 1. The instrumental setup consists of three modules: (i) the catalytic reaction unit, (ii) the CryoF unit, and (iii) a triple quadrupole (TQ) mass spectrometer. The catalytic reaction unit (labeled as "Reactor" in Scheme 1) operated under continuous flow, enabling photocatalytic reactions to be performed in the presence of a preselected gas composition (via three independent gas inlets for introduction of $\mathrm{NO}, \mathrm{O}_{2}$, and $\mathrm{N}_{2}$ ). Prior to mixing $\mathrm{NO}$ with $\mathrm{N}_{2}$ and $\mathrm{O}_{2}$, the $\mathrm{N}_{2}$ and $\mathrm{O}_{2}$ flows could be directed to bubble through or bypass a water bubbler, thus allowing control of humidity in the catalytic reaction chamber. Please note that the data presented in Figures 1, 2, and 4 were obtained using the experimental setup as shown in Scheme 1 and did not utilize GC which will be discussed further in subsequent sections.

In the CryoF unit, reaction products from the photoreactor were preconcentrated in the trap element. After removing most of the residual $\mathrm{N}_{2}$ and $\mathrm{O}_{2}$ with a $\mathrm{He}$ gas purge, cryofocused reaction products were flash-heated and introduced into the TQ mass spectrometer. Two miniature three-way pulse valves (labeled as "V1" and "V2" in Scheme 1) (Model VAC-250, Parker Hannifin Corp., Cleveland, $\mathrm{OH}$ ) were used to control gas flow pathways during the cryofocusing and $\mathrm{He}$ gas purge periods. The valve "V1" operating in "normally open" mode (i.e., not actuated) allowed gas to flow from the reaction unit into the CryoF trap element (CTE) for preconcentrating reaction products; when valve "V1" was "closed" (i.e., actuated), He purge gas flowed into the CTE. The valve "V2" operating in "normally open" mode directed CTE gas flow into an exhaust vacuum pump; once valve "V2" was "closed", the gas flow containing the desorbed preconcentrated analytes (after resistive heating of the CTE) was directed into the TQ mass spectrometer.

In the TQ mass spectrometer, the photocatalytic reaction products were detected in real time following the CryoF and subsequent He purge times. A typical sequence of events used in this study was as follows: (1) photocatalytic reaction products were transferred into the trap element for a predefined period of time (e.g., typically $60 \mathrm{~s}$ cryofocusing time to preconcentrate analytes), (2) "V1" was energized and $\mathrm{He}$ (back-pressure of $5 \mathrm{psi}$ ) was introduced to purge the trap element for $60 \mathrm{~s}$, (3) the CTE was flash-heated for $100 \mathrm{~ms}$ and 

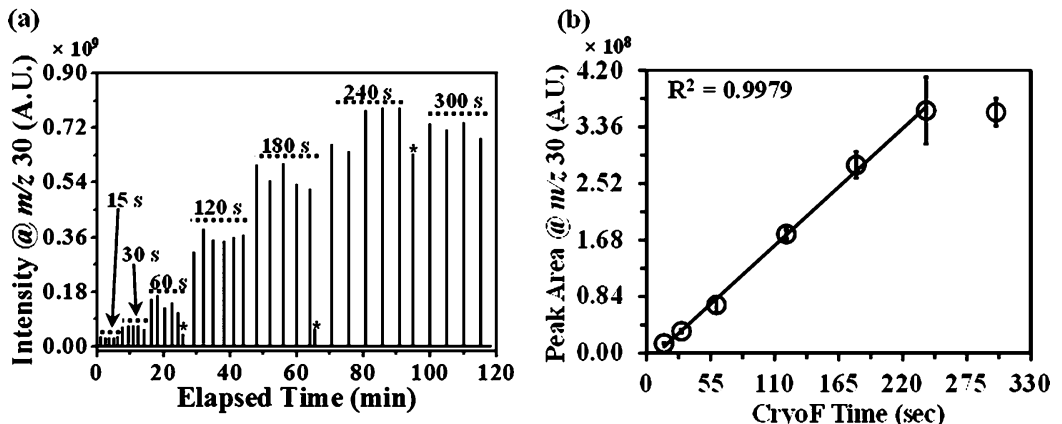

Figure 2. (a) Selected ion chromatogram (SIC) for $\mathrm{NO}^{\bullet+}(\mathrm{m} / z$ 30) at varied cryofocusing times $(15-300 \mathrm{~s})$. (b) Plot of average peak area as a function of cryofocusing time at $80 \mathrm{ppm}$ of $\mathrm{NO}$ concentration. Error bars are reported at the $95 \%$ confidence level for $n=5$ experimental trials.

"V2" was immediately energized to transfer the trapped compounds into TQ mass spectrometer for $100 \mathrm{~ms}$, (4) TQMS data (continuous acquisition) were acquired, and (5) "V1" and "V2" were de-energized to return to step 1. These steps were repeated continuously for the entirety of each experimental run.

3.2. Detection of $\mathrm{NO}, \mathrm{N}_{2} \mathrm{O}$, and $\mathrm{NO}_{2}$ in the Absence of $\mathrm{TiO}_{2}$ Catalyst and UV Light. Figure 1 shows the representative selected ion chromatograms (SICs) for (a) $\mathrm{NO}^{\bullet+}\left(\mathrm{m} / z\right.$ 30), (b) $\mathrm{N}_{2} \mathrm{O}^{\bullet+}(\mathrm{m} / z 44)$, and (c) $\mathrm{NO}_{2}{ }^{\bullet+}(\mathrm{m} / z$ 46), in the absence of $\mathrm{TiO}_{2}$ catalyst and UV light, collected after a cryofocusing time of $60 \mathrm{~s}$ and inlet $\mathrm{NO}$ concentration of $80 \mathrm{ppm}$. Results from the CryoF/TQMS showed sharp, symmetric, and reproducible MS peaks that yielded SIC peak widths of $\sim 2 \mathrm{~s}$ (measured at peak base). In Figure 1a, the MS signal intensity for $\mathrm{NO}^{\bullet+}(\mathrm{m} / z 30)$ is $\sim 90$ - and $\sim 16$-fold higher than the MS signal intensities for $\mathrm{N}_{2} \mathrm{O}^{\bullet+}(\mathrm{m} / z$ 44) (Figure $1 \mathrm{~b}$, inset) and $\mathrm{NO}_{2}{ }^{\circ+}(\mathrm{m} / z 46)$, respectively (Figure $1 \mathrm{c}$, inset). The larger MS signal intensity for $\mathrm{NO}^{\bullet+}$ was expected, as the final gas composition was primarily $\mathrm{NO}$ in simulated air. Although $\mathrm{N}_{2}$ and $\mathrm{O}_{2}$ were still detectable by the mass spectrometer, $\mathrm{N}_{2}$ and $\mathrm{O}_{2}$ signals were low compared with that of $\mathrm{NO}$ due to the He purge segment of the experiment (which allowed for $\mathrm{N}_{2}$ and $\mathrm{O}_{2}$ gases to escape to the exhaust system through "V2", as shown in Scheme 1). The presence of $\mathrm{N}_{2} \mathrm{O}$ was a result of trace $\mathrm{N}_{2} \mathrm{O}$ impurity in the $\mathrm{NO}$ gas composition (confirmed using GC-MS), potentially generated in the copper ${ }^{59,60}$ transfer line between the gas tank and MFC. The presence of $\mathrm{NO}_{2}$ likely results from minor noncatalytic oxidation reaction of $\mathrm{NO}$ in the presence of oxygen. ${ }^{61}$ In order to examine the effects of cryofocusing time on the signal response of $\mathrm{NO}$, we performed MS experiments measuring NO signal intensity as a function of cryofocusing time.

Figure 2a shows the SIC for $\mathrm{NO}^{\bullet+}($ at $m / z 30)$ at increasing cryofocusing times (from 15 to $300 \mathrm{~s}$ ). The $\mathrm{NO}$ gas composition for the data shown in Figure 2 was the same as that used in Figure 1. A linear increase in signal intensity for $\mathrm{NO}^{\bullet+}$ was observed as the cryofocusing time was increased (e.g., an $\sim 4$-fold increase in $\mathrm{NO}^{\bullet+}$ signal intensity was observed when the cryofocusing time was increased from 30 to $120 \mathrm{~s}$ ). It is important to note that the flash heating temperature must be sufficient to desorb all trapped analytes at each cryofocusing cycle. For the experiments reported here, we utilized an optimized flash heating time of $100 \mathrm{~ms}$ to ensure complete desorption of all $\mathrm{NO}_{x}$ and $\mathrm{N}_{2} \mathrm{O}$ species. No significant changes in $\mathrm{NO}^{\bullet+}$ signal intensity was observed after $240 \mathrm{~s}$ cryofocusing time (i.e., the $\mathrm{NO}^{\bullet+}$ signal intensities at 240 and $300 \mathrm{~s}$ cryofocusing time are similar) due to the saturation of the EM detector. The peaks denoted with asterisks in Figure 2a were of lower intensity (due to a system reset upon changing cryofocusing time that resulted in premature analyte release from the CTE) and were not used for the calculations in Figure $2 \mathrm{~b}$.

Figure $2 \mathrm{~b}$ shows the calibration line for $\mathrm{NO}^{\bullet+}$ signal intensity (measured as the chromatographic peak area for $\mathrm{m} / z$ 30) detected as a function of cryofocusing time using data from Figure 2a. Each data point (denoted with empty circles) in Figure $2 \mathrm{~b}$ corresponds to an average of five experimental trials with error bars reported at the $95 \%$ confidence level. The $R$ squared $\left(R^{2}\right)$ value $(0.9979)$ was obtained using the linear regression function in Microsoft Excel (Microsoft Office 7, Microsoft Corporation, Redmond, WA) for data acquired over a cryofocusing time range of $15-240 \mathrm{~s}$ (deemed to be the "linear range" 62 for this setup). MS Data at $300 \mathrm{~s}$ cryofocusing time was not utilized for determining the $R^{2}$ value because the $\mathrm{NO}^{\bullet+}$ signal intensity was outside the linear range of the MS detection system. In the absence of analyte standards, internal calibrants can be used to calculate unknown concentrations. To estimate the concentrations of $\mathrm{N}_{2} \mathrm{O}$ and $\mathrm{NO}_{2}$, we used $\mathrm{NO}$ as the internal calibrant and corrected for detector response factor (i.e., IS differences between $\mathrm{NO}, \mathrm{N}_{2} \mathrm{O}$ (1.66), and $\mathrm{NO}_{2}$ (1.39)). ${ }^{56,57}$ Because the freezing points for $\mathrm{NO}, \mathrm{N}_{2} \mathrm{O}$, and $\mathrm{NO}_{2}$ are all above liquid nitrogen temperature (i.e., $>77 \mathrm{~K}$ ), cryofocusing efficiencies for these analytes were assumed to be similar.

3.3. Compositional and Structural Analysis of $\mathrm{TiO}_{2}$ Catalysts. $\mathrm{TiO}_{2}$ crystals have three naturally occurring polymorphisms including anatase (tetragonal), rutile (tetragonal), and brookite (orthorhombic). ${ }^{63}$ Anatase and rutile structured $\mathrm{TiO}_{2}$ are the primary constituents of the P25 catalyst. $^{64}$ To verify the purity and characterize the $\mathrm{TiO}_{2}$ catalysts (i.e., P25, "pure anatase", and "rutile-rich") utilized in this work, we analyzed each catalyst using powder XRD. In Figure 3, normalized intensities from the P25, pure anatase, and rutile-rich $\mathrm{TiO}_{2}$ catalysts are plotted against scattering angle. Based on the XRD data (calculations using eq 1), ${ }^{51}$ anatase and rutile compositions (by mass) were obtained for P25 (Figure $3 \mathrm{a}$ ) as $85.9 \%$ anatase $/ 14.1 \%$ rutile, for pure anatase (Figure $3 \mathrm{~b}$ ) as $96.9 \%$ anatase $/ 3.1 \%$ rutile, and for rutile-rich (Figure $3 c$ ) as $25.2 \%$ anatase $/ 74.8 \%$ rutile. The XRD data were insufficient to determine $100 \%$ compositional purity for the pure anatase catalyst sample due to signal-to-noise limitations. No rutile peaks were observed in the XRD spectra; hence, we presumed the sample to be "pure" anatase. Additionally, calcination of the pure anatase $\mathrm{TiO}_{2}$, using the procedure outlined by $\mathrm{Li}$ et al., ${ }^{65}$ did not result in any significant change in the appearance of 


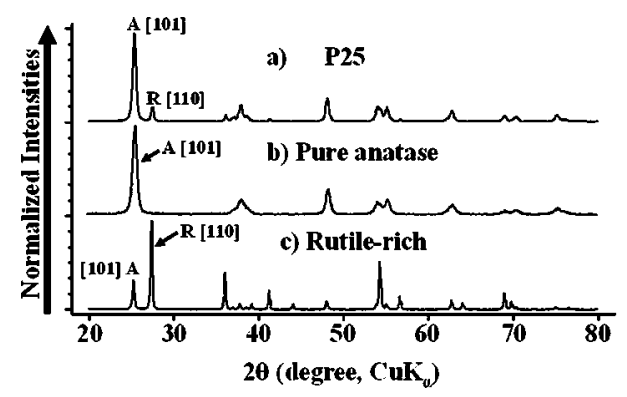

Figure 3. XRD spectra of (a) P25, (b) pure anatase, and (c) rutile-rich $\mathrm{TiO}_{2}$ catalysts. Letters "A" and " $\mathrm{R}$ " represent the anatase and rutile peaks utilized in the catalyst composition calculations, respectively.

XRD spectra or photocatalytic reactivity, supporting the assumption that any rutile fraction was minimal. Commercially available P25 titania photocatalyst composition has been previously reported as $78 \mathrm{wt} \%$ anatase, $14 \mathrm{wt} \%$ rutile, and 8 wt $\%$ amorphous phases. ${ }^{49}$ Amorphicity of the pure anatase and rutile-rich catalysts is unknown at this time.

TEM images of pure anatase particles (Figure S1a) showed homogeneous short rod-shaped nanoparticles (average diameter: $28.14 \pm 13.16 \mathrm{~nm}, n=400)$. Rutile-rich nanoparticles (Figure S1b), however, showed three distinct particle size distributions (average diameter: $81.09 \pm 51.53 \mathrm{~nm}, n=400$ ) possibly representing the separate anatase, rutile, and amorphous components. P25 nanoparticles (Figure S1c), despite also being a biphasic mixture like the rutile-rich nanoparticles, were observed to be mostly spherical and of uniform size (average diameter: $26.04 \pm 8.68 \mathrm{~nm}, n=400$ ).

3.4. Photocatalytic Reaction of NO in the Presence of $\mathrm{TiO}_{2}$. We used the instrumental setup depicted in Scheme 1 to analyze the products of the previously reported photocatalytic reaction of $\mathrm{NO}$ in the presence of $\mathrm{P} 25$, pure anatase, and rutilerich $\mathrm{TiO}_{2}$ photocatalysts when exposed to UV radiation. ${ }^{31}$ When $\mathrm{TiO}_{2}$ is exposed to incident UV radiation at $365 \mathrm{~nm}$, an electron is excited to yield an electron-hole $\left(\mathrm{e}^{-}-\mathrm{h}^{+}\right)$pair. This excited electron can relax back (i.e., recombination) into the unoccupied molecular orbitals of the adsorbed species on the $\mathrm{TiO}_{2}$ 's surface. ${ }^{66}$ However, if this electron-hole pair is localized at the surface, it can also act as an individual electron donor and electron acceptor and impact NO decomposition. ${ }^{31}$ In this study, the conventionally used standard photocatalyst, P25 $\mathrm{TiO}_{2}$, was investigated for its ability to catalyze the reduction of $\mathrm{NO}$ into $\mathrm{N}_{2} \mathrm{O}$. P25 $\mathrm{TiO}_{2}$ used in this experiment was a biphasic mixture of anatase and rutile nanoparticles (Figure $3 \mathrm{a}$ ) with an average diameter of $21 \mathrm{~nm} .{ }^{64}$ Furthermore, the photocatalytic efficiency of pure anatase $\mathrm{TiO}_{2}$ and rutile-rich $\mathrm{TiO}_{2}$ were compared with that of the $\mathrm{P} 25 \mathrm{TiO}_{2}$ catalyst. It is believed that the electron-hole pairs from the excited $\mathrm{TiO}_{2}$ form primarily on the anatase nanoparticles and the smaller rutile nanoparticles function to facilitate charge transfer to the anatase nanoparticles and slow down the electron-hole recombination. ${ }^{67}$ The efficient electron-hole separation with lower recombination rates observed in $\mathrm{P} 25 \mathrm{TiO}_{2}$ (possessing mixed anatase-rutile phase ratios) has made $\mathrm{P} 25 \mathrm{TiO}_{2}$ a benchmark for photocatalytic reaction studies. ${ }^{67}$ However, the increased photoactivity of P25, due to proximal rutile and anatase particles, has been argued against. ${ }^{49}$

Figure 4 shows the temporal plots of normalized ion intensities for the $\mathrm{NO}, \mathrm{N}_{2} \mathrm{O}$, and $\mathrm{NO}_{2}$ species at $80 \mathrm{ppm}$ of $\mathrm{NO}$ (in simulated air) and a cryofocusing time of $60 \mathrm{~s}$ in the
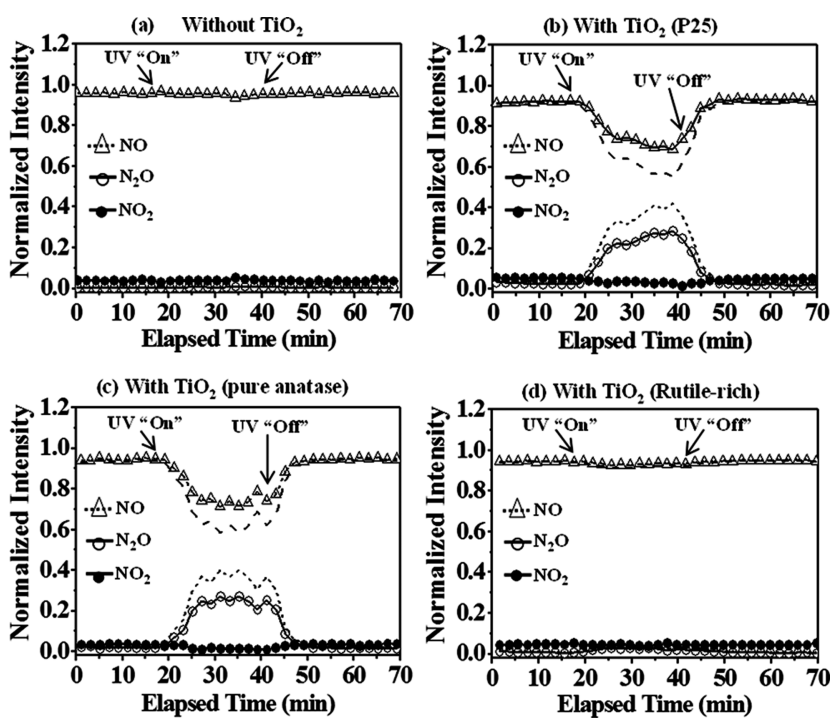

Figure 4. Temporal plots of normalized ion intensities (i.e., peak areas) for $\mathrm{NO}, \mathrm{N}_{2} \mathrm{O}$, and $\mathrm{NO}_{2}$ (a) without $\mathrm{TiO}_{2}$ catalyst, (b) with $\mathrm{TiO}_{2}$ (P25), (c) with $\mathrm{TiO}_{2}$ (pure anatase), and (d) with $\mathrm{TiO}_{2}$ (rutilerich) catalysts. NO concentration was $80 \mathrm{ppm}$ in simulated air. Dashed and short dashed lines represent $\mathrm{NO}$ and $\mathrm{N}_{2} \mathrm{O}$ normalized ion intensities, respectively, corrected for the $\mathrm{NO}^{\bullet+}$ fragment ion contribution from the parent $\mathrm{N}_{2} \mathrm{O}^{\bullet+}$ ion as a result of EI fragmentation.

presence/absence of UV light and $\mathrm{TiO}_{2}$ catalysts. In Figure 4, symbols denoted by empty triangles, empty circles, and solid circles represent $\mathrm{NO}, \mathrm{N}_{2} \mathrm{O}$, and $\mathrm{NO}_{2}$ ion intensities, respectively. The plots shown in dashed and short dashed lines in Figures $4 \mathrm{~b}$ and $4 \mathrm{c}$ correspond to the normalized ion intensities of $\mathrm{NO}$ and $\mathrm{N}_{2} \mathrm{O}$ corrected for $\mathrm{NO}^{\bullet+}$ fragment ion contribution from EI fragmentation of $\mathrm{N}_{2} \mathrm{O}^{\bullet+}$, respectively. Normalized ion intensities for the $\mathrm{NO}, \mathrm{N}_{2} \mathrm{O}$, and $\mathrm{NO}_{2}$ species were obtained by dividing the total ion intensity of each $\mathrm{NO}$, $\mathrm{N}_{2} \mathrm{O}$, and $\mathrm{NO}_{2}$ species by the sum of the total ion intensities from $\mathrm{NO}, \mathrm{N}_{2} \mathrm{O}$, and $\mathrm{NO}_{2}$ species at each time (or data) point. UV radiation was applied (indicated by the arrow symbol and UV "On") at an elapsed time of $17 \mathrm{~min}$ and stopped (indicated by the arrow symbol and UV "Off") at an elapsed time of 42 min. Hence, the catalytic reaction chamber was exposed to UV radiation for $25 \mathrm{~min}$ and was manually covered with aluminum foil to keep the chamber dark outside the UV exposure period.

In Figure 4a, the normalized ion intensities for $\mathrm{NO}, \mathrm{N}_{2} \mathrm{O}$, and $\mathrm{NO}_{2}$ were obtained without any $\mathrm{TiO}_{2}$ catalyst in the reaction chamber to determine the variation of the $\mathrm{NO}, \mathrm{N}_{2} \mathrm{O}$, and $\mathrm{NO}_{2}$ species as a result of UV radiation (control). The temporal plot in Figure $4 \mathrm{a}$ shows that ion intensities for the $\mathrm{NO}, \mathrm{N}_{2} \mathrm{O}$, and $\mathrm{NO}_{2}$ species do not change significantly throughout the duration of the experiment and are independent of UV radiation exposure. As expected, NO ion intensities were consistently higher than $\mathrm{N}_{2} \mathrm{O}$ and $\mathrm{NO}_{2}$ ion intensities, and the observed ion intensity trends for the $\mathrm{NO}, \mathrm{N}_{2} \mathrm{O}$, and $\mathrm{NO}_{2}$ species corroborate with the results observed in Figure 1. The lack of any significant change (i.e., $>5 \%$ ) in ion intensities for the $\mathrm{NO}, \mathrm{N}_{2} \mathrm{O}$, and $\mathrm{NO}_{2}$ species suggests that in the absence of the $\mathrm{TiO}_{2}$ catalyst UV radiation does not play an important role in the conversion of NO.

To examine the effects of the $\mathrm{TiO}_{2}$ catalyst on the conversion of $\mathrm{NO}$ to $\mathrm{N}_{2} \mathrm{O}$ and $\mathrm{NO}_{2}, \sim 0.50 \mathrm{~g}$ of P25, pure anatase, or rutile-rich $\mathrm{TiO}_{2}$ photocatalysts was individually loaded into the 
reaction chamber. Figures $4 \mathrm{~b}-\mathrm{d}$ show the normalized ion intensities for the $\mathrm{NO}, \mathrm{N}_{2} \mathrm{O}$, and $\mathrm{NO}_{2}$ species in the presence of the $\mathrm{P} 25$, pure anatase, and rutile-rich $\mathrm{TiO}_{2}$ catalysts during separate experiments. As shown in Figure $4 \mathrm{~b}$, the normalized ion intensities of $\mathrm{NO}, \mathrm{N}_{2} \mathrm{O}$, and $\mathrm{NO}_{2}$, prior to the application of UV radiation (from elapsed time of 0 to $17 \mathrm{~min}$ ), were stable and followed a similar trend to that observed without the catalyst (as in Figure 4a). Upon exposure of the P25 $\mathrm{TiO}_{2}$ catalyst to UV radiation (starting at an elapsed time of $17 \mathrm{~min}$ ), a significant (i.e., $>5 \%$ ) decrease in $\mathrm{NO}$ ion intensities and an associated increase in $\mathrm{N}_{2} \mathrm{O}$ ion intensities were observed. However, when the exposure of $\mathrm{P} 25 \mathrm{TiO}_{2}$ photocatalyst to UV radiation was terminated or turned "off" (at 42 min elapsed time), $\mathrm{NO}$ and $\mathrm{N}_{2} \mathrm{O}$ ion intensities returned to their initial levels after a 5-10 min delay (i.e., comparable to their respective ion intensities prior to exposure to UV radiation).

The notable changes in $\mathrm{NO}$ and $\mathrm{N}_{2} \mathrm{O}$ ion intensities, in response to the $\mathrm{P} 25 \mathrm{TiO}_{2}$ photocatalysts exposure to $\mathrm{UV}$ radiation, suggest that $\mathrm{N}_{2} \mathrm{O}$ was the major photocatalytic product of NO. No significant (i.e., $>5 \%$ ) changes were observed in $\mathrm{NO}_{2}$ ion intensity in either the presence or absence of $\mathrm{P} 25 \mathrm{TiO}_{2}$ photocatalyst exposed to UV radiation.

The pure anatase $\mathrm{TiO}_{2}$ photocatalyst showed trends similar to the $\mathrm{P} 25 \mathrm{TiO}_{2}$ photocatalyst for variations in $\mathrm{NO}, \mathrm{N}_{2} \mathrm{O}$, and $\mathrm{NO}_{2}$ ion intensities during the UV radiation "on" period. In Figure $4 \mathrm{c}$, ion intensity for $\mathrm{NO}$ decreased and ion intensity for $\mathrm{N}_{2} \mathrm{O}$ increased when $\mathrm{NO}$ was exposed to the pure anatase $\mathrm{TiO}_{2}$ photocatalyst in the presence of $\mathrm{UV}$ radiation, and no significant (i.e., $>5 \%$ ) change in $\mathrm{NO}_{2}$ ion intensity was observed.

Photocatalytic activity of the rutile-rich $\mathrm{TiO}_{2}$ catalyst was considered insignificant ( $\sim 2 \%$ decrease in $\mathrm{NO}$ ion intensity), in comparison to the P25 ( $\sim 32 \%$ decrease in NO ion intensity) and pure anatase $\mathrm{TiO}_{2}(\sim 31 \%$ decrease in $\mathrm{NO}$ ion intensity) catalysts, for the conversion of $\mathrm{NO}$ to $\mathrm{N}_{2} \mathrm{O}$. For example, in Figure $4 \mathrm{~d}$ only minor (i.e., $<5 \%$ ) changes were seen for the ion intensities of $\mathrm{NO}$ and $\mathrm{N}_{2} \mathrm{O}$ during the exposure of $\mathrm{NO}$ to $\mathrm{UV}$ radiation in the presence of the rutile-rich $\mathrm{TiO}_{2}$ photocatalyst. Low photocatalytic activity of rutile $\mathrm{TiO}_{2}$ catalyst for conversion of $\mathrm{NO}$ to $\mathrm{N}_{2} \mathrm{O}$ in the presence of $\mathrm{UV}$ radiation has been previously reported. ${ }^{67}$

It is known that $\mathrm{NO}_{2}$ dimerizes to dinitrogen tetroxide $\left(\mathrm{N}_{2} \mathrm{O}_{4}\right)$ at lower temperatures (i.e., $<-10{ }^{\circ} \mathrm{C}$ ), but at temperatures $>140{ }^{\circ} \mathrm{C}, \mathrm{N}_{2} \mathrm{O}_{4}$ converts back to $\mathrm{NO}_{2}$ gas. ${ }^{68,69}$ To verify if $\mathrm{NO}_{2}$ is detected intact (i.e., not partially lost due to degradation or dimerization) in the mass spectrometer after trapping (at $\sim-196{ }^{\circ} \mathrm{C}$, i.e., $\mathrm{LN}_{2}$ temperature) and desorption (at $>150{ }^{\circ} \mathrm{C}$ ), we performed cryofocusing experiments utilizing pure $\mathrm{NO}_{2}$ samples to monitor the effects of cryofocusing on $\mathrm{NO}_{2}$. Under identical experimental conditions (i.e., He purge period, cryofocusing duration, flash heating duration and temperature, and mass spectrometry parameters) to other photocatalytic experiments reported in the article, the standard $\mathrm{NO}_{2}$ sample was detected in the mass spectrometer with no detectable $\mathrm{NO}_{2}$ degradation products other than its fragment ions (e.g., ion at $\mathrm{m} / \mathrm{z} 30$ from fragmentation of $\mathrm{NO}_{2}$ and potential residual NO (see Figure 5)).

Also, $\mathrm{N}_{2} \mathrm{O}_{4}{ }^{\bullet+}$ (the ionized dimer of $\mathrm{NO}_{2}$ at $\mathrm{m} / z$ 92) was not detected (at either 70 or $20 \mathrm{eV}$ electron energies) by the mass spectrometer during any of the experiments involving the photocatalytic reaction of $\mathrm{NO}$.

Summation of $\mathrm{NO}$ and $\mathrm{N}_{2} \mathrm{O}$ signals was higher during $\mathrm{UV}$ radiation exposure in the presence of $\mathrm{TiO}_{2}$ (Figures $4 \mathrm{~b}$ and

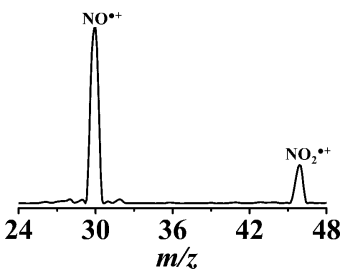

Figure 5. EI (at $70 \mathrm{eV})$ mass spectrum for standard $\mathrm{NO}_{2}($ at $m / z$ 46) showing its major fragment ion at $m / z 30$.

Figure 4c) than in the absence of $\mathrm{TiO}_{2}$ (Figure 4a). It might initially be expected that the summation of $\mathrm{NO}$ and $\mathrm{N}_{2} \mathrm{O}$ ion intensities should in fact be less during photocatalytic conversion as the stoichiometry of $\mathrm{NO} \rightarrow \mathrm{N}_{2} \mathrm{O}$ is 2:1, respectively. However, it should be noted that $\mathrm{NO}^{\bullet+}$ is a commonly observed fragment ion of $\mathrm{N}_{2} \mathrm{O}$ (in the EI mass spectrum $)^{70}$ and will contribute to the overall $\mathrm{NO}^{\bullet+}$ signal intensity. To correct for the contribution of $\mathrm{NO}^{\bullet+}$ resulting from the fragmentation of $\mathrm{N}_{2} \mathrm{O}^{\bullet+}$ during $\mathrm{EI}$ (at $70 \mathrm{eV}$ ) to the overall $\mathrm{NO}^{\bullet+}$ signal intensity, we performed EI experiments using a standard $\mathrm{N}_{2} \mathrm{O}$ sample under similar experimental (i.e., CryoF and MS) conditions as the data presented in Figure 4. The calculated $\mathrm{NO}^{\bullet+}$ to $\mathrm{N}_{2} \mathrm{O}^{\bullet+}$ ratio (i.e., 0.474) from the standard $\mathrm{N}_{2} \mathrm{O}$ was used to obtain the ion intensity contribution of $\mathrm{NO}^{\bullet+}$ from $\mathrm{N}_{2} \mathrm{O}^{\bullet+}$ fragmentation. The calculated intensity of $\mathrm{NO}^{\bullet+}$ from $\mathrm{N}_{2} \mathrm{O}^{\bullet+}$ fragmentation was then subtracted from the total $\mathrm{NO}^{\bullet+}$ signal intensity (data shown in dashed lines in Figures $4 \mathrm{~b}$ and $4 \mathrm{c}$ ) and added to the total ion intensity for $\mathrm{N}_{2} \mathrm{O}^{\bullet+}$ (data shown in short dashed lines in Figures $4 \mathrm{~b}$ and $4 \mathrm{c}$ ). Another potential method to eliminate the contribution of $\mathrm{NO}^{\bullet+}$ from the fragmentation of $\mathrm{N}_{2} \mathrm{O}^{\bullet+}$ to the overall ion intensity of $\mathrm{NO}^{\bullet+}$ is to perform EI experiments at lower electron energies (e.g., $<24 \mathrm{eV}$ ) and avoid $\mathrm{NO}^{\bullet+}$ fragment ion formation. Conducting EI at lower electron energy minimizes fragmentation but results in an overall reduction in sensitivity. ${ }^{71}$ We conducted EI experiments at $20 \mathrm{eV}$ (the lowest electron energy available on our MS system) on the standard $\mathrm{N}_{2} \mathrm{O}$ sample and continued to observe $\mathrm{NO}^{\bullet+}$ signal from the fragmentation of $\mathrm{N}_{2} \mathrm{O}^{\bullet+}$ but with approximately 1 order of magnitude loss in sensitivity. Thus, we utilized the calculated $\mathrm{NO}^{\bullet+}$ to $\mathrm{N}_{2} \mathrm{O}^{\bullet+}$ ratio (obtained with $\mathrm{EI}$ at electron energy of 70 $\mathrm{eV}$ ) to correct for the contribution of $\mathrm{NO}^{\bullet+}$ (resulting from the fragmentation of $\mathrm{N}_{2} \mathrm{O}^{\bullet+}$ ) to the overall $\mathrm{NO}^{\bullet+}$ signal intensity.

In a separate experiment, a GC system was used to confirm the identity of the $\mathrm{N}_{2} \mathrm{O}$ produced during the catalytic decomposition of NO. A transfer line was inserted from valve 2 ("V2" in Scheme 1) into a GC injection port to introduce the cryogenically trapped catalysis reaction products into the GC before MS detection. The GC effluent was then introduced into the MS system for $m / z$ analysis. Retention time of the $\mathrm{N}_{2} \mathrm{O}$ generated during photocatalysis was then compared to the retention time of a standard $\mathrm{N}_{2} \mathrm{O}$ gas sample. The standard $\mathrm{N}_{2} \mathrm{O}$ gas sample was placed into a sealed $40 \mathrm{~mL}$ glass vial and transferred to the CTE element of the CryoF Unit (using a transfer line connected to valve \#1 (labeled as "V1" in Scheme 1)) for cryofocusing and subsequent desorption and introduction into the GC injection port. No other experimental parameters for the catalysis unit, CryoF, or mass spectrometer were modified for the aforementioned GC experiments.

The GC retention time of $\mathrm{N}_{2} \mathrm{O}$ (from the photocatalysis of $\mathrm{NO}$ in the presence of $\mathrm{P} 25 \mathrm{TiO}_{2}$ and UV light) was $2.004 \pm$ $0.004 \mathrm{~min}$ (at 95\% confidence level; $n=3$ ) (see Figure 6). The 


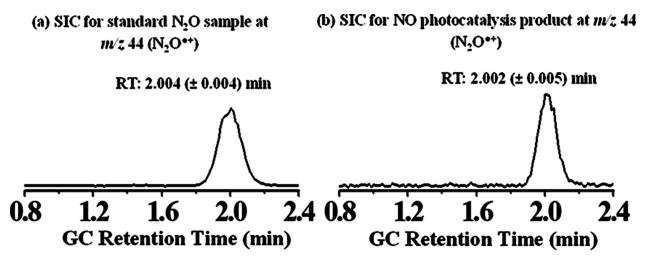

Figure 6. Selected ion chromatograms (SICs) of (a) standard $\mathrm{N}_{2} \mathrm{O}$ sample at $m / z 44\left(\mathrm{~N}_{2} \mathrm{O}^{\circ+}\right)$ and (b) NO photocatalysis product at $\mathrm{m} / z$ $44\left(\mathrm{~N}_{2} \mathrm{O}^{\circ+}\right)$ obtained from GC/MS analyses. The values on top of the peaks are the average retention times (RTs) for the SIC peak maxima at $m / z 44$ from triplicate experiments (the error at $95 \%$ CL is included in parentheses for each value).

GC retention time of the standard $\mathrm{N}_{2} \mathrm{O}$ sample was $2.002 \pm$ $0.005 \mathrm{~min}$ (at $95 \%$ confidence level; $n=3$ ) (see Figure 6). Under the same GC/MS conditions, retention time for $\mathrm{CO}_{2}$ (which also generates an ion at $m / z 44$ ) was $1.488 \pm 0.035 \mathrm{~min}$ (at $95 \%$ confidence level; $n=3$ ). The retention time for the $\mathrm{N}_{2} \mathrm{O}$ product of the photocatalytic reaction of NO statistically matched with the retention time of the standard $\mathrm{N}_{2} \mathrm{O}$ (based on student $t$ test at $95 \%$ confidence level) and, combined with its mass spectral pattern, allowed us to confirm the identity of the $\mathrm{N}_{2} \mathrm{O}$ photocatalytic product.

Additional sets of experiments were performed (to deduce the role of $\mathrm{O}_{2}$ gas), where only $\mathrm{NO}$ and $\mathrm{N}_{2}$ (i.e., no $\mathrm{O}_{2}$ ) were introduced into the photocatalytic reaction chamber; similar trends for $\mathrm{NO}$ and $\mathrm{NO}_{2}$ profiles (i.e., decrease in both $\mathrm{NO}^{\bullet+}$ and $\mathrm{NO}_{2}{ }^{\circ+}$ intensities) were observed in the presence and absence of $\mathrm{O}_{2}$ gas. However, we did not observe any conversion of $\mathrm{NO}$ to $\mathrm{N}_{2} \mathrm{O}$ in the absence of $\mathrm{O}_{2}$.

Figure 7 shows the ion intensities for the $\mathrm{NO}, \mathrm{N}_{2} \mathrm{O}$, and $\mathrm{NO}_{2}$ species in the presence of the $\mathrm{P} 25 \mathrm{TiO}_{2}$ catalyst and nitrogen gas (i.e., without any $\mathrm{O}_{2}$ gas). Upon exposure of the $\mathrm{P} 25 \mathrm{TiO}_{2}$ catalyst to UV radiation (indicated by UV "on" and the dashed closed arrow symbol at an elapsed time of 16 to $47 \mathrm{~min}$ ), a significant (i.e., $>5 \%$ ) decrease in $\mathrm{NO}$ and $\mathrm{NO}_{2}$ ion intensities
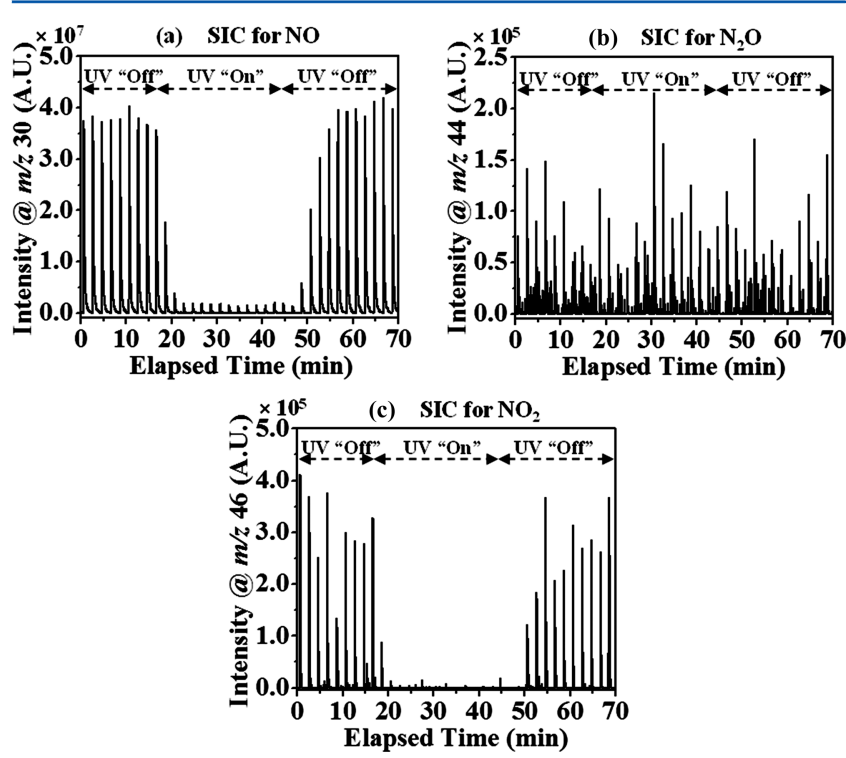

Figure 7. Representative selected ion chromatograms (SICs) for (a) $\mathrm{NO}^{\bullet+}(\mathrm{m} / z 30)$, (b) $\mathrm{N}_{2} \mathrm{O}^{\bullet+}(\mathrm{m} / z 44)$, and (c) $\mathrm{NO}_{2}{ }^{\bullet+}(\mathrm{m} / z$ 46) in the presence of $\mathrm{P} 25 \mathrm{TiO}_{2}$ catalyst and UV light. NO concentration was 80 ppm in nitrogen environment. Arrows indicating UV "off" and "on" durations are placed on top of the SICs. was observed and no change in $\mathrm{N}_{2} \mathrm{O}$ ion intensity was detected. When the exposure of $\mathrm{P} 25 \mathrm{TiO}_{2}$ photocatalyst to $\mathrm{UV}$ radiation was terminated (indicated by UV "off" and the dashed closed arrow symbol at initial elapsed time of $47 \mathrm{~min}$ ), $\mathrm{NO}$ and $\mathrm{NO}_{2}$ ion intensities returned to their initial levels and $\mathrm{N}_{2} \mathrm{O}$ ion intensity remained unchanged. It is possible that $\mathrm{NO}$ is being converted into $\mathrm{N}_{2}$ species though we did not notice any significant increase in $\mathrm{N}_{2}{ }^{-+}$intensity. $\mathrm{N}_{2}$ is still a potential product from the photocatalytic decomposition of $\mathrm{NO}$ in the absence of $\mathrm{O}_{2}$, but results remain inconclusive due to the inherent limitations of trapping $\mathrm{N}_{2}$ gas using a $\mathrm{LN}_{2}$ cryofocuser. Future experiments with the use of $\mathrm{NO}$ gas balanced in helium will be performed to verify this hypothesis.

One of the major features of the $\mathrm{TiO}_{2}$ photocatalyst is the availability of oxygen vacancies on its surface. Two $\mathrm{Ti}^{3+}$ sites are present at each oxygen vacancy, which are the primary locations for NO adsorption. Based on a previously reported mechanism, ${ }^{2,12}$ the photocatalytic conversion of $\mathrm{NO}$ to $\mathrm{N}_{2} \mathrm{O}$ on $\mathrm{Ti}^{3+}$ might potentially involve the following suggested reaction steps:

$$
\begin{aligned}
& \mathrm{TiO}_{2}+h v \rightarrow \mathrm{e}^{-}+\mathrm{h}^{+} \\
& \mathrm{H}_{2} \mathrm{O}_{(\mathrm{ads})}+\mathrm{h}^{+} \rightarrow \mathrm{OH}_{(\mathrm{ads})}^{\bullet}+\mathrm{H}^{+} \\
& \mathrm{NO}_{(\mathrm{ads})}+\mathrm{e}^{-} \rightarrow \mathrm{N}_{(\mathrm{ads})}+\mathrm{O}_{(\mathrm{ads})}^{-} \\
& \mathrm{O}_{2 \text { (ads) }}+\mathrm{e}^{-} \rightarrow \mathrm{O}_{2}^{-} \text {(ads) } \\
& \mathrm{NO}_{(\mathrm{ads})}+\mathrm{O}_{2}^{-}{ }_{(\text {ads })} \rightarrow \mathrm{NO}_{3}^{-}{ }_{(\mathrm{ads})} \\
& \mathrm{NO}_{2(\mathrm{ads})}+\mathrm{OH}_{(\mathrm{ads})}^{\bullet} \rightarrow \mathrm{HNO}_{3(\mathrm{ads})} \\
& \mathrm{NO}_{(\text {ads })}+\mathrm{N}_{(\text {ads })} \rightarrow \mathrm{N}_{2} \mathrm{O}_{(\mathrm{ads})} \\
& \mathrm{O}_{(\text {ads })}+\mathrm{Ti}^{3+} \rightarrow \mathrm{Ti}^{4+}+\mathrm{O}^{2-} \text { (lattice) } \\
& \mathrm{O}_{2}^{-}{ }_{(\text {ads })} \rightarrow \mathrm{O}_{(\text {ads })}^{-}+\mathrm{O}_{(\text {ads })} \\
& \mathrm{O}_{(\text {ads })}^{-} \rightarrow \mathrm{O}_{(\text {ads })}+\mathrm{e}^{-} \\
& 2 \mathrm{~N}_{(\mathrm{ads})}+\mathrm{O}_{(\mathrm{ads})} \rightarrow \mathrm{N}_{2} \mathrm{O}_{(\mathrm{ads})} \\
& \mathrm{N}_{2} \mathrm{O}_{(\text {ads })} \rightarrow \mathrm{N}_{2} \mathrm{O}_{(\text {gas })}
\end{aligned}
$$

Briefly, the photocatalytic conversion of $\mathrm{NO}$ to $\mathrm{N}_{2} \mathrm{O}$ involves the adsorption of gas-phase $\mathrm{NO}$ molecules to the oxygen vacancies on the $\mathrm{TiO}_{2}$ surface to form adsorbed $\mathrm{NO}$ molecules (i.e., $\left.\mathrm{NO}_{(\text {ads })}\right)$. Oxygen $\left(\mathrm{O}_{2}\right)$ and water $\left(\mathrm{H}_{2} \mathrm{O}\right)$ molecules also

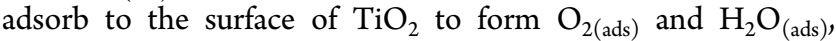
respectively. An electron generated from $\mathrm{TiO}_{2}$ 's exposure to incident UV radiation (step 1) cleaves the $\mathrm{N}-\mathrm{O}$ and $\mathrm{O}-\mathrm{O}$ bonds in $\mathrm{NO}_{(\mathrm{ads})}$ and $\mathrm{O}_{2(\mathrm{ads})}$ to form an adsorbed nitrogen atom (i.e., $\mathrm{N}_{(\mathrm{ads})}$ ) and an adsorbed oxygen anion (i.e., $\mathrm{O}^{-}($ads) (step 3) and $\mathrm{O}_{2}^{-}$(ads) (step 4), respectively. The electron hole (i.e., $\mathrm{h}^{+}$) generated in step 1 reacts with $\mathrm{H}_{2} \mathrm{O}_{(\mathrm{ads})}$ molecules to form adsorbed hydroxyl radical $\left(\mathrm{OH}^{\bullet}{ }_{\text {ads })}\right)$ and hydrogen ion $\left(\mathrm{H}^{+}\right)$(step 2). $\mathrm{OH}^{\bullet}$ can also form when hydroxyl anion (i.e., $\mathrm{OH}^{-}$) reacts with $\mathrm{h}^{+}$(i.e., $\mathrm{OH}^{-}($ads $\left.)+\mathrm{h}^{+} \rightarrow \mathrm{OH}^{\bullet}{ }_{(\text {ads })}\right)$. The oxygen anion (i.e., $\mathrm{O}_{2}{ }^{-}$(ads) $)$may react with $\mathrm{NO}_{(\text {ads })}$ or $\mathrm{NO}_{2 \text { (ads) }}$ to form $\mathrm{NO}_{3}{ }^{-}$(ads) which stays bound to the surface of $\mathrm{TiO}_{2}$

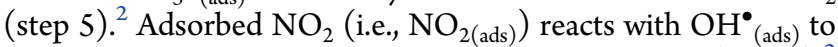
form $\mathrm{HNO}_{3}{ }^{\circ}$ (ads) which remains on the $\mathrm{TiO}_{2}$ surface (step 6). ${ }^{2}$ An additional $\mathrm{NO}_{(\text {ads })}$ reacts with $\mathrm{N}_{(\text {ads })}$ to form adsorbed $\mathrm{N}_{2} \mathrm{O}$ (i.e., $\mathrm{N}_{2} \mathrm{O}_{(\text {ads })}$ ) (step 7) which can in turn lose its oxygen atom 
and diffuse as $\mathrm{N}_{2}$ gas (i.e., $\mathrm{N}_{2} \mathrm{O}_{(\mathrm{g})}+\mathrm{e}^{-} \rightarrow \mathrm{N}_{2(\mathrm{~g})}+\mathrm{O}^{-}($ads $)$). In addition, the oxygen anion (i.e., $\mathrm{O}^{-}{ }_{(\text {ads })}$ ) generated from $\mathrm{NO}$ dissociation (step 3 ) remains in the filled oxygen vacancy as $\mathrm{O}^{2-}{ }_{\text {(lattice) }}$ (step 8). The adsorbed superoxide, $\mathrm{O}_{2}{ }^{-}$(ads) (formed in step 4), dissociates to form adsorbed peroxide $\left(\mathrm{O}^{-}\right)_{(\mathrm{ads})}$ and adsorbed atomic oxygen $(\mathrm{O})_{(\text {ads })}($ step 9$)$. Adsorbed peroxide $\left(\mathrm{O}^{-}\right)_{(\text {ads })}$ loses its electron $\left(\mathrm{e}^{-}\right)$to form adsorbed atomic oxygen $(\mathrm{O})_{(\text {ads })}($ step 10). Consequently, the adsorbed oxygen atom $(\mathrm{O})_{(\text {ads })}$ reacts with two adsorbed nitrogen atoms $(2 \mathrm{~N})_{(\text {ads })}$ to form adsorbed $\mathrm{N}_{2} \mathrm{O}_{(\text {ads })}$ according to the reaction mechanism proposed by Larson et al. ${ }^{72}$ Steps 7-9, while speculative, provide a potential explanation for the notable lack of observable $\mathrm{N}_{2} \mathrm{O}$ formation in the absence of $\mathrm{O}_{2}$ gas. However, the loss of an oxygen atom requires a sufficiently long $\mathrm{N}_{2} \mathrm{O}$ residence time at an oxygen vacancy; otherwise, it can desorb as $\mathrm{N}_{2} \mathrm{O}_{\text {(gas) }}$ (step 12 ). Kim et al. ${ }^{14}$ reported that $\mathrm{N}_{2} \mathrm{O}$ does not dissociate on $\mathrm{TiO}_{2}$ surface to form $\mathrm{N}_{2}$ and $\mathrm{O}$. Moreover, it has been reported that $\mathrm{N}_{2} \mathrm{O}$ molecules are only weakly bound to the $\mathrm{TiO}_{2}$ surface with an adsorption energy of $7.73 \mathrm{kcal} / \mathrm{mol}$; ${ }^{13}$ thus, it is likely that in this photocatalyzed reaction most of the $\mathrm{N}_{2} \mathrm{O}_{(\text {ads })}$ were desorbed as $\mathrm{N}_{2} \mathrm{O}_{\text {(gas) }}$ to yield the observed MS signal at $\mathrm{m} / z 44$.

The importance of water in the photocatalytic decomposition of $\mathrm{NO}$ in the presence of $\mathrm{TiO}_{2}$ catalysts has previously been demonstrated. ${ }^{2,73}$ To explore the role of $\mathrm{H}_{2} \mathrm{O}$ in the NO photocatalysis mechanism, we conducted experiments identical to the aforementioned experiments (i.e., the photocatalytic conversion of $\mathrm{NO}$ using $\mathrm{P} 25 \mathrm{TiO}_{2}$ catalyst) in the absence of water (i.e., $0 \%$ relative humidity) and in the presence of varying concentrations of water (0-23\% relative humidity) (Figure 8). Initial experiments (as shown in Figure 8) displayed an increase in signal intensities for $\mathrm{NO}^{\bullet+}, \mathrm{NO}_{2}{ }^{\bullet+}$, and $\mathrm{N}_{2} \mathrm{O}^{\bullet+}$ as humidity was increased. More notably, the increase in $\mathrm{N}_{2} \mathrm{O}^{\circ+}$ (Figure 8b) signal intensity occurred separately (i.e., $\sim 40 \mathrm{~min}$ prior) from the increases in signal intensity for $\mathrm{NO}^{\bullet+}$ (Figure 8a) and $\mathrm{NO}_{2}{ }^{\bullet+}$ (Figure $8 \mathrm{c}$ ). However, after the exposure of the P25 $\mathrm{TiO}_{2}$ catalyst to $80 \mathrm{ppm}$ of $\mathrm{NO}$ and $\mathrm{UV}$ radiation in the absence of humidity (i.e., $0 \%$ relative humidity), the subsequent introduction of humidity resulted in similar releases of $\mathrm{NO}^{\bullet+}$, $\mathrm{NO}_{2}^{\bullet+}$, and $\mathrm{N}_{2} \mathrm{O}^{\bullet+}$ (even in the absence of UV radiation). Thus, the trends observed in Figure 8 are due to an initial increase in humidity facilitating the release of already formed $\mathrm{N}_{2} \mathrm{O}$ (from $\mathrm{TiO}_{2}$ surface) and followed by further humidity increases releasing bound $\mathrm{NO}$ and $\mathrm{NO}_{2}$ from the $\mathrm{TiO}_{2}$ surface.

In the presence of high concentrations of $\mathrm{H}_{2} \mathrm{O}$ (i.e., at $70 \pm$ $2 \%$ relative humidity), we observed similar trends (i.e., decrease in $\mathrm{NO}^{\bullet+}$ and $\mathrm{NO}_{2}{ }^{++}$and increase in $\mathrm{N}_{2} \mathrm{O}^{\bullet+}$ intensities) to the results obtained at lower relative humidity (i.e., at $24 \pm 2 \%$, data shown in Figure 4b) during the photocatalytic decomposition of $\mathrm{NO}$ in the presence of $\mathrm{P} 25 \mathrm{TiO}_{2}$ catalyst but with a $15 \%$ lower overall NO conversion efficiency (shown in Figure S2). Although it is known that $\mathrm{H}_{2} \mathrm{O}$ provides hydroxyl radicals $\left(\mathrm{HO}^{\circ}\right)$ which play a key role in the photocatalytic oxidization of $\mathrm{NO}$ (formation of $\mathrm{NO}_{2}$ and $\mathrm{HNO}_{3}$ ), some reports have also stated that increases in humidity levels reduce the catalytic conversion efficiency of NO in the presence of P25 $\mathrm{TiO}_{2}$ photocatalysts. $^{74,75}$ For example, Ao et al. reported that $\mathrm{H}_{2} \mathrm{O}$ vapor competes with $\mathrm{NO}$ adsorption sites on the $\mathrm{TiO}_{2}$ surface; thus, increasing the $\mathrm{H}_{2} \mathrm{O}$ vapor pressure reduces the availability of $\mathrm{TiO}_{2}$ active sites for $\mathrm{NO}$ photocatalysis. ${ }^{74,75}$ Hence, we surmise that the reduction in overall NO conversion efficiency observed in our experiments (in the presence of high
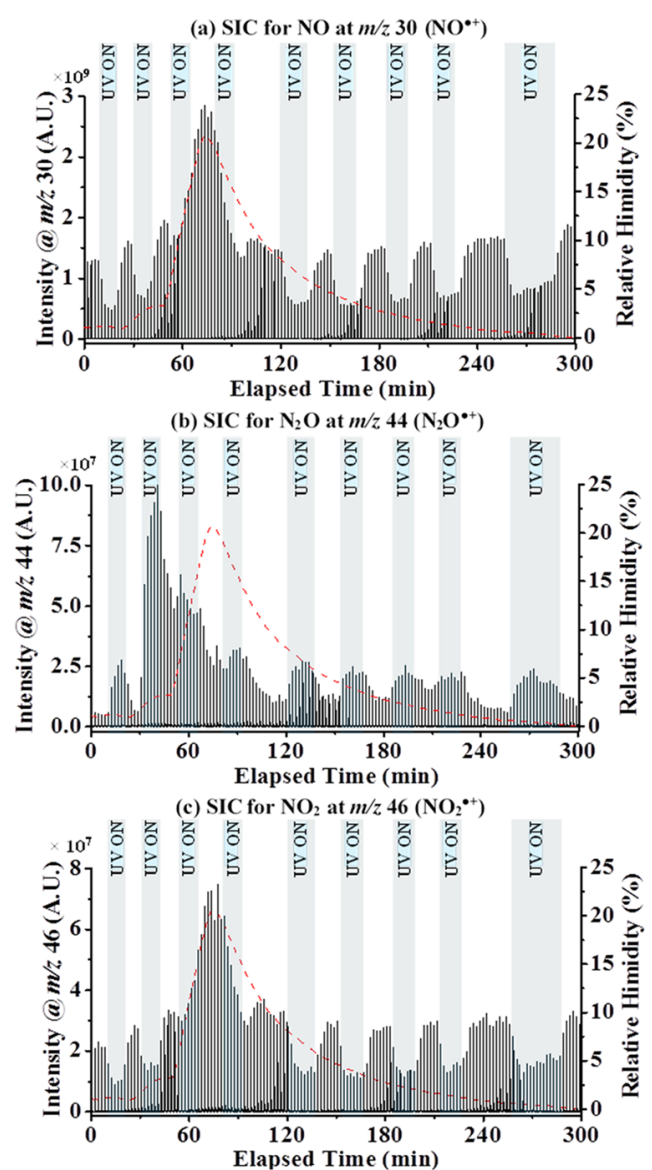

Figure 8. Representative selected ion chromatograms (SICs) for (a) $\mathrm{NO}^{\bullet+}(\mathrm{m} / z 30)$, (b) $\mathrm{N}_{2} \mathrm{O}^{\circ+}(\mathrm{m} / z 44)$, and (c) $\mathrm{NO}_{2}{ }^{\bullet+}(\mathrm{m} / z 46)$ in the presence of $\mathrm{P} 25 \mathrm{TiO}_{2}$ catalyst, UV light (shown in blue-colored rectangular boxes and "UV ON"), and increasing relative humidity $(0-23 \%)$. NO concentration was $80 \mathrm{ppm}$ in simulated air. The red dotted lines overlaid on the SIC represent the relative humidity (\%) of the catalytic reaction chamber during the experiment.

$\mathrm{H}_{2} \mathrm{O}$ vapor pressure) is because of the competition between $\mathrm{H}_{2} \mathrm{O}$ and NO for adsorption sites on the $\mathrm{TiO}_{2}$ surface.

\section{CONCLUSION}

We designed and constructed a novel photocatalytic reaction chamber coupled to a custom-built liquid nitrogen cryofocusing unit for mass spectrometry analysis and monitoring of nitrogen oxide species. Results from the detection of NO in the absence of $\mathrm{TiO}_{2}$ catalyst indicate that $\mathrm{NO}$ ion intensity increases linearly with cryofocusing time. We also showed that the major photocatalytic reaction product of the decomposition of $\mathrm{NO}$ in the presence of $\mathrm{P} 25 \mathrm{TiO}_{2}$ and pure anatase $\mathrm{TiO}_{2}$ is $\mathrm{N}_{2} \mathrm{O}$. We anticipate the use of the cryofocusing/mass spectrometry unit coupled to the photocatalytic reaction chamber for further examination of the photocatalytic decomposition of $\mathrm{NO}$ in the presence of different photocatalysts and with varying experimental conditions.

\section{ASSOCIATED CONTENT}

\section{S Supporting Information}

The Supporting Information is available free of charge on the ACS Publications website at DOI: 10.1021/acs.jpcc.5b10631.

Figure S1: representative TEM images of (a) pure anatase, (b) rutile-rich, and (c) $\mathrm{P} 25 \mathrm{TiO}_{2}$ nanoparticles 
used in this study; Figure S2: temporal plots of normalized ion intensities for $\mathrm{NO}, \mathrm{N}_{2} \mathrm{O}$, and $\mathrm{NO}_{2}$ with P25 $\mathrm{TiO}_{2}$ catalyst at $70 \pm 2 \%$ relative humidity (PDF)

\section{AUTHOR INFORMATION}

\section{Corresponding Author}

*Tel 254-710-2678, e-mail Touradj_Solouki@baylor.edu (T.S.).

\section{Present Address}

B.Z.: Agilent Technologies, Inc., Santa Clara, CA 95051.

\section{Notes}

The authors declare no competing financial interest.

\section{ACKNOWLEDGMENTS}

The authors acknowledge the financial support provided by the National Science Foundation (NSF) (grant award \#s 1346596 and 1455668). Any opinions, findings, conclusions, or recommendations expressed in this material are those of the authors' and do not necessarily reflect the views of the NSF. D.A.E. and E.O. acknowledge the financial support from the Scientific and Technological Research Council of Turkey (TUBITAK) (Project Code: 113Z543). The authors also thank Mr. David LeBrecque (University of Maine, Orono, ME) for constructing the capacitor bank used in these experiments, Dr. Boris Lau (Baylor University, Waco, TX) for providing the pure anatase and rutile-rich $\mathrm{TiO}_{2}$ catalysts, and Dr. Murugaeson R. Kumar (Baylor University, Waco, TX) for preparing and providing the standard $\mathrm{NO}_{2}$ sample utilized in this study. Thanks to Mr. Joe McCulloch of the machine shop at Baylor Sciences Building (Baylor University, Waco, TX) for assisting in construction of the catalytic reaction chamber. The authors thank Dr. Bernd Zechmann (Center for Microscopy and Imaging, Baylor University, Waco, TX) for technical support during microscopy and image analysis.

\section{REFERENCES}

(1) Dalton, J. S.; Janes, P. A.; Jones, N. G.; Nicholson, J. A.; Hallam, K. R.; Allen, G. C. Photocatalytic Oxidation of NO Gases Using $\mathrm{TiO}_{2}$ : A Surface Spectroscopic Approach. Environ. Pollut. 2002, 120, 415422.

(2) Lasek, J.; Yu, Y.-H.; Wu, J. C. S. Removal of $\mathrm{NO}_{\mathrm{x}}$ by Photocatalytic Processes. J. Photochem. Photobiol., C 2013, 14, 29-52.

(3) Bowman, C. T. Control of Combustion-Generated Nitrogen Oxide Emissions: Technology Driven by Regulation. Symp. (Int.) Combust., [Proc.] 1992, 24, 859-878.

(4) Newton, M. A.; Dent, A. J.; Diaz-Moreno, S.; Fiddy, S. G.; Evans, J. Rapid Phase Fluxionality as the Determining Factor in Activity and Selectivity of Highly Dispersed, $\mathrm{Rh} / \mathrm{Al}_{2} \mathrm{O}_{3}$ in $\mathrm{DeNO} \mathrm{x}_{\mathrm{x}}$ Catalysis. Angew. Chem., Int. Ed. 2002, 41, 2587-2589.

(5) Savara, A.; Sachtler, W. M. H.; Weitz, E. TPD of $\mathrm{NO}_{2}{ }^{-}$and $\mathrm{NO}_{3}{ }^{-}$ from Na-Y: The Relative Stabilities of Nitrates and Nitrites in Low Temperature $\mathrm{DeNO}_{\mathrm{x}}$ Catalysis. Appl. Catal., B 2009, 90, 120-125.

(6) Heiredal, M. L.; Jensen, A. D.; Thogersen, J. R.; Frandsen, F. J.; Friemann, J.-U. Pilot-Scale Investigation and Cfd Modeling of Particle Deposition in Low-Dust Monolithic SCR DeNO ${ }_{x}$ Catalysts. AIChE J. 2013, 59, 1919-1933.

(7) Dettmer, K.; Engewald, W. Practical Gas Chromatography: A Comprehensive Reference; Springer: New York, 2014; p 1410.

(8) Haj, K. O.; Schneider, S.; Maire, G.; Zyade, S.; Ziyad, M.; Garin, F. Influence of Alumina-Supported M-Pt Catalysts in $\mathrm{DeNO}_{x}$ Reactions with $\mathrm{M}=\mathrm{Pd}$ or Ir or Ru. Top. Catal. 2001, 16/17, 205-208.

(9) Trichard, J. M. Chapter 7 Current Tasks and Challenges for Exhaust after-Treatment Research: An Industrial Viewpoint. Stud. Surf. Sci. Catal. 2007, 171, 211-233.
(10) Yamashita, H.; Ichihashi, Y.; Anpo, M.; Hashimoto, M.; Louis, C.; Che, M. Photocatalytic Decomposition of $\mathrm{NO}$ at $275 \mathrm{~K}$ on Titanium Oxides Included within Y-Zeolite Cavities: The Structure and Role of the Active Sites. J. Phys. Chem. 1996, 100, 16041-16044.

(11) Yamashita, H.; Ichihashi, Y.; Zhang, S. G.; Matsumura, Y.; Souma, Y.; Tatsumi, T.; Anpo, M. Photocatalytic Decomposition of $\mathrm{NO}$ at $275 \mathrm{~K}$ on Titanium Oxide Catalysts Anchored within Zeolite Cavities and Framework. Appl. Surf. Sci. 1997, 121/122, 305-309.

(12) Lu, G.; Linsebigler, A.; Yates, J. J. T. Ti ${ }^{3+}$ Defect Sites on $\mathrm{TiO}_{2}$ (110): Production and Chemical Detection of Active Sites. J. Phys. Chem. 1994, 98, 11733-11738.

(13) Sorescu, D. C.; Rusu, C. N.; Yates, J. J. T. Adsorption of NO on the $\mathrm{TiO}_{2}(110)$ Surface: An Experimental and Theoretical Study. J. Phys. Chem. B 2000, 104, 4408-4417.

(14) Kim, B.; Li, Z.; Kay, B. D.; Dohnalek, Z.; Kim, Y. K. Unexpected Nondissociative Binding of $\mathrm{N}_{2} \mathrm{O}$ on Oxygen Vacancies on a Rutile $\mathrm{TiO}_{2}(110)-1 \times 1$. J. Phys. Chem. C 2012, 116, 1145-1150.

(15) Dupart, Y.; Fine, L.; D’Anna, B.; George, C. Heterogeneous Uptake of $\mathrm{NO}_{2}$ on Arizona Test Dust under Uv-a Irradiation: An Aerosol Flow Tube Study. Aeolian Res. 2014, 15, 45-51.

(16) Todorova, N.; Giannakopoulou, T.; Karapati, S.; Petridis, D.; Vaimakis, T.; Trapalis, C. Composite $\mathrm{TiO}_{2} /$ Clays Materials for Photocatalytic $\mathrm{NO}_{x}$ Oxidation. Appl. Surf. Sci. 2014, 319, 113-120.

(17) Polat, M.; Soylu, A. M.; Erdogan, D. A.; Erguven, H.; Vovk, E. I.; Ozensoy, E. Influence of the Sol-Gel Preparation Method on the Photocatalytic NO Oxidation Performance of $\mathrm{TiO}_{2} / \mathrm{Al}_{2} \mathrm{O}_{3}$ Binary Oxides. Catal. Today 2015, 241, 25-32.

(18) Chen, X.; Selloni, A. Introduction: Titanium Dioxide $\left(\mathrm{TiO}_{2}\right)$ Nanomaterials. Chem. Rev. 2014, 114, 9281-9282.

(19) Schneider, J.; Matsuoka, M.; Takeuchi, M.; Zhang, J.; Horiuchi, Y.; Anpo, M.; Bahnemann, D. W. Understanding $\mathrm{TiO}_{2}$ Photocatalysis: Mechanisms and Materials. Chem. Rev. 2014, 114, 9919-9986.

(20) Tuazon, E. C.; Winer, A. M.; Graham, R. A.; Schmid, J. P.; Pitts, J. J. N. Fourier-Transform Infrared Detection of Nitramines in Irradiated Amine- $\mathrm{NO}_{x}$ Systems. Environ. Sci. Technol. 1978, 12, 954958.

(21) Wojtas, J.; Bielecki, Z.; Stacewicz, T.; Mikolajczyk, J.; Medrzycki, R; Rutecka, B. Application of Quantum Cascade Lasers in Nitric Oxide and Nitrous Oxide Detection. Acta Phys. Polym., A 2011, 120, 794-797.

(22) McClenny, W. A.; Williams, E. J.; Cohen, R. C.; Stutz, J. Preparing to Measure the Effects of the $\mathrm{NO}_{\mathrm{x}}$ Sip Call- Methods for Ambient Air Monitoring of $\mathrm{NO}, \mathrm{NO}_{2}, \mathrm{NO}_{\mathrm{y}}$, and Individual $\mathrm{NO}_{z}$ Species. J. Air Waste Manage. Assoc. 2002, 52, 542-562.

(23) Pijolat, C.; Pupier, C.; Testud, C.; Lalauze, R.; Montanaro, L.; Negro, A.; Malvicino, C. Electrochemical Sensors for CO/NO Detection in Automotive Applications. J. Electroceram. 1998, 2, 181191.

(24) Kipping, P. J.; Jeffery, P. G. Detection of Nitric Oxide by GasChromatography. Nature 1963, 200, 1314-1314.

(25) Topsoe, N. Y.; Topsoe, H.; Dumesic, J. A. Vanadian/Titania Catalyst for Selective Catalytic Reduction (SCR) of Nitric Oxide by Ammonia: I. Combined Temperature-Programmed in-Situ Ftir and on-Line Mass Spectroscopy Studies. J. Catal. 1995, 151, 226-240.

(26) Kinoue, T.; Asai, S.; Ishii, Y.; Ishikawa, K.; Fujii, M.; Nakano, K.; Hasumi, K. Direct Determination of Trace Nitrogen Dioxide by Atmospheric Pressure Lonization Mass Spectrometry (APIMS) without Conversion to Nitric Oxide. Environ. Health Prev. Med. 2000, 5, 97-102.

(27) Houtman, N.; Solouki, T.; Lad, R. J.; Freeman, C. A Breath of ...: Doctors Could One Day Check Your Health by Analyzing Your Breath. Chem. Br. 2003, 39, 28-31.

(28) Fredrick, G.; Solouki, T.; Riker, R.; Lad, R. J. In Breath Diagnostic Sensors as a Triage Tool for Pathogen Exposure, AVS Topical Conference on Understanding and Operating in Threat Environments, Monterey, CA, 2002.

(29) Down, R. D.; Lehr, J. H. Environmental Instrumentation and Analysis Handbook; Wiley-Interscience: Hoboken, NJ, 2005; p 1068. 
(30) Zhang, J.; Ayusawa, T.; Minagawa, M.; Kinugawa, K.; Yamashita, H.; Matsuoka, M.; Anpo, M. Investigations of $\mathrm{TiO}_{2}$ Photocatalysts for the Decomposition of NO in the Flow System - the Role of Pretreatment and Reaction Conditions in the Photocatalytic Efficiency. J. Catal. 2001, 198, 1-8.

(31) Soylu, A. M.; Polat, M.; Erdogan, D. A.; Say, Z.; Yildirim, C.; Birer, O.; Ozensoy, E. $\mathrm{TiO}_{2}-\mathrm{Al}_{2} \mathrm{O}_{3}$ Binary Mixed Oxide Surfaces for Photocatalytic $\mathrm{NO}_{x}$ Abatement. Appl. Surf. Sci. 2014, 318, 142-149.

(32) Courbon, H.; Pichat, P. Room-Temperature Interaction of $\mathrm{N}^{18} \mathrm{O}$ with Ultraviolet-Illuminated Titanium Dioxide. J. Chem. Soc., Faraday Trans. 1 1984, 80, 3175-3185.

(33) Hu, S.; Apple, T. M. ${ }^{15}$ n NMR Study of the Adsorption of NO and $\mathrm{NH}_{3}$ on Titania-Supported Vanadia Catalysts. J. Catal. 1996, 158, 199-204.

(34) Rusu, C. N.; Yates, J. J. T. Photochemistry of NO Chemisorbed on $\mathrm{TiO}_{2}(110)$ and $\mathrm{TiO}_{2}$ Powders. J. Phys. Chem. B 2000, 104, 17291737.

(35) Henderson, M. A.; Szanyi, J.; Peden, C. H. F. Conversion of $\mathrm{N}_{2} \mathrm{O}$ to $\mathrm{N}_{2}$ on $\mathrm{TiO}_{2}$ (110). Catal. Today 2003, 85, 251-266.

(36) Freitag, J.; Dominguez, A.; Niehaus, T. A.; Hulsewig, A.; Dillert, R.; Frauenheim, T.; Bahnemann, D. W. Nitrogen (Ii) Oxide Charge Transfer Complexes on $\mathrm{TiO}_{2}$ : A New Source for Visible-Light Activity. J. Phys. Chem. C 2015, 119, 4488-4501.

(37) Kisch, H.; Bahnemann, D. Best Practice in Photocatalysis: Comparing Rates or Apparent Quantum Yields? J. Phys. Chem. Lett. 2015, 6, 1907-1910.

(38) Howitt, C.; Pitchon, V.; Maire, G. Influence of Oxygen on the Performance of a Three-Way Catalyst. J. Catal. 1995, 154, 47-55.

(39) Cant, N. W.; Angove, D. E.; Chambers, D. C. Nitrous Oxide Formation During the Reaction of Simulated Exhaust Streams over Rhodium, Platinum and Palladium Catalysts. Appl. Catal., B 1998, 17, 63-73.

(40) Mejia-Centeno, I.; Martinez-Hernandez, A.; Fuentes, G. A. Effect of Low-Sulfur Fuels Upon $\mathrm{Nh}_{3}$ and $\mathrm{N}_{2} \mathrm{O}$ Emission During Operation of Commercial Three-Way Catalytic Converters. Top. Catal. 2007, 42-43, 381-385.

(41) Granger, P.; Parvulescu, V. I. Catalytic $\mathrm{NO}_{x}$ Abatement Systems for Mobile Sources: From Three-Way to Lean Burn after-Treatment Technologies. Chem. Rev. 2011, 111, 3155-3207.

(42) Ozensoy, E.; Peden, C. H. F.; Szanyi, J. $\mathrm{NO}_{2}$ Adsorption on Ultrathin $\Theta-\mathrm{Al}_{2} \mathrm{O}_{3}$ Films: Formation of Nitrite and Nitrate Species. J. Phys. Chem. B 2005, 109, 15977-15984.

(43) Mikhaylov, R. V.; Lisachenko, A. A.; Shelimov, B. N.; Kazansky, V. B.; Martra, G.; Alberto, G.; Coluccia, S. FTIR and TPD Analysis of Surface Species on a $\mathrm{TiO}_{2}$ Photocatalyst Exposed to NO CO, and NOCO Mixtures: Effect of Uv-Vis Light Irradiation. J. Phys. Chem. C 2009, 113, 20381-20387.

(44) de Zeeuw, J. Can I Analyze NO, $\mathrm{N}_{2} \mathrm{O}$ and $\mathrm{NO}_{2}$ via GC; http:// Blog.Restek.Com/? $\mathrm{P}=4583$, last accessed April 28, 2015.

(45) Sich, I.; Russow, R. ${ }^{15} \mathrm{n}$ Analysis of Nitric Oxide and Nitrous Oxide by Cryotrap Enrichment Using a Gas Chromatograph Quadrupole Mass Spectrometer and Its Application to ${ }^{15} \mathrm{n}$-Tracer Investigations of $\mathrm{NO} / \mathrm{N}_{2} \mathrm{O}$ Formation in Soil. Rapid Commun. Mass Spectrom. 1999, 13, 1325-1328.

(46) Lim, T. H.; Jeong, S. M.; Kim, S. D.; Gyenis, J. Photocatalytic Decomposition of NO by $\mathrm{TiO}_{2}$ Particles. J. Photochem. Photobiol., A 2000, 134, 209-217.

(47) Heo, I.; Kim, M. K.; Sung, S.; Nam, I.-S.; Cho, B. K.; Olson, K. L.; Li, W. Combination of Photocatalysis and HC/SCR for Improved Activity and Durability of $\mathrm{DeNO}_{x}$ Catalysts. Environ. Sci. Technol. 2013, 47, 3657-3664.

(48) Ao, C. H.; Lee, S. C. Enhancement Effect of $\mathrm{TiO}_{2}$ Immobilized on Activated Carbon Filter for the Photodegradation of Pollutants at Typical Indoor Air Level. Appl. Catal., B 2003, 44, 191-205.

(49) Ohtani, B.; Prieto-Mahaney, O. O.; Li, D.; Abe, R. What Is Degussa (Evonik) P25? Crystalline Composition Analysis, Reconstruction from Isolated Pure Particles and Photocatalytic Activity Test. J. Photochem. Photobiol., A 2010, 216, 179-182.
(50) Petrusevski, V. M.; Taseska, M.; Monkovic, M. Reaction of Copper with Fuming Nitric Acid: A Novel Lecture Experiment in Passivation. Chem. Educ. 2005, 10, 208-210.

(51) Bakardjieva, S.; Subrt, J.; Stengl, V.; Dianez, M. J.; Sayagues, M. J. Photoactivity of Anatase-Rutile $\mathrm{TiO}_{2}$ Nanocrystalline Mixtures Obtained by Heat Treatment of Homogeneously Precipitated Anatase. Appl. Catal., B 2005, 58, 193-202.

(52) Sabyrov, K.; Burrows, N. D.; Penn, R. L. Size-Dependent Anatase to Rutile Phase Transformation and Particle Growth. Chem. Mater. 2013, 25, 1408-1415.

(53) Jacoby, C. B.; Remple, D. L.; Gross, M. L. In A Cold Trap/ Pulsed Valve GC/FTMS Interface: Ultra-Trace Analysis, Proceeding of the 38th ASMS Conference on Mass Spectrometry and Allied Topics, Tucson, AZ, 1990; pp 840-841.

(54) Luo, Z.; Heffner, C.; Solouki, T. Multidimensional GC-Fourier Transform Ion Cyclotron Resonance MS Analyses: Utilizing GasPhase Basicities to Characterize Multicomponent Gasoline Samples. J. Chromatogr. Sci. 2009, 47, 75-82.

(55) Banzi, M. Getting Started with Arduino; O’Reilly Media, Inc.: 2009.

(56) Nakao, F. Determination of the Ionization Guage Sensitivity Using the Relative Ionization Cross-Section. Vacuum 1975, 25, 431435 .

(57) Bartmess, J. E.; Georgiadis, R. M. Empirical Methods for Determination of Ionization Gauge Relative Sensitivities for Different Gases. Vacuum 1983, 33, 149-153.

(58) Miller, T. M. Atomic and Molecular Polarizabilities. In CRC Handbook of Chemistry and Physics, 95th ed.; Lide, D. R., Frederikse, H. P. R., Eds.; CRC Press Inc.: Baton Rouge, LA, 2014; pp 193-202.

(59) Brown, W. A.; Sharma, R. K.; King, D. A.; Hag, S. Adsorption and Reactivity of $\mathrm{NO}$ and $\mathrm{N}_{2} \mathrm{O}$ on $\mathrm{Cu}\{110\}$ : Combined Rairs and Molecular Beam Studies. J. Phys. Chem. 1996, 100, 12559-12568.

(60) Dumas, P.; Suhren, M.; Chabal, Y. J.; Hirschmugl, C. J.; Williams, G. P. Adsorption and Reactivity of $\mathrm{NO}$ on $\mathrm{Cu}(111)$ : A Synchrotron Infrared Reflection Absorption Spectroscopic Study. Surf. Sci. 1997, 371, 200-212.

(61) Wiberg, E.; Wiberg, N.; Holleman, A. F. Inorganic Chemistry; Academic Press: San Diego, 2001; Vol. 1 p 1884.

(62) Harris, D. C. Quantitative Chemical Analysis, 8th ed.; W.H. Freeman and Company: New York, 2010; Chapter 4, pp 68-95.

(63) Diebold, U. The Surface Science of Titanium Dioxide. Surf. Sci. Rep. 2003, 48, 53-229.

(64) Sigma-Aldrich, Titanium(IV) Oxide; http://Www.Sigmaaldrich. Com/Catalog/Product/Aldrich/718467?Lang=En\&Region=Us, last accessed June 30, 2015.

(65) Li, G.; Li, L.; Boerio-Goates, J.; Woodfield, B. F. High Purity Anatase $\mathrm{TiO}_{2}$ Nanocrystals: Near Room-Temperature Synthesis, Grain Growth Kinetics, and Surface Hydration Chemistry. J. Am. Chem. Soc. 2005, 127, 8659-8666.

(66) Shapovalov, V.; Stefanovich, E. V.; Truong, T. N. Nature of the Excited States of the Rutile $\mathrm{TiO}_{2}(110)$ Surface with Adsorbed Water. Surf. Sci. 2002, 498, L103-L108.

(67) Hurum, D. C.; Agrios, A. G.; Gray, K. A.; Rajh, T.; Thurnauer, M. C. Explaining the Enhanced Photocatalytic Activity of Degussa P25 Mixed-Phase $\mathrm{TiO}_{2}$ Using Epr. J. Phys. Chem. B 2003, 107, 4545-4549.

(68) Yu, Q.; Gao, H. A Simple Determination of the $\mathrm{NO}_{2}$ Dimerization Equilibrium Constant. J. Chem. Educ. 1997, 74, 233234.

(69) Leenson, I. A. Approaching Equilibrium in the $\mathrm{N}_{2} \mathrm{O}_{4}-\mathrm{NO}_{2}$ System: A Common Mistake in Textbooks. J. Chem. Educ. 2000, 77, $1652-1655$.

(70) Southan, G. J.; Srinivasan, A. Nitrogen Oxides and Hydroxyguanidines: Formation of Donors of Nitric and Nitrous Oxides and Possible Relevance to Nitrous Oxide Formation by Nitric Oxide Synthase. Nitric Oxide 1998, 2, 270-286.

(71) Vekey, K. Internal Energy Effects in Mass Spectrometry. J. Mass Spectrom. 1996, 31, 445-463. 
(72) Larson, R. S.; Pihl, J. A.; Chakravarthy, V. K.; Toops, T. J.; Daw, C. S. Microkinetic Modeling of Lean $\mathrm{NO}_{x}$ Trap Chemistry under Reducing Conditions. Catal. Today 2008, 136, 104-120.

(73) Devahasdin, S.; Fan, C.; Li, K. J.; Chen, D. H. TiO Photocatalytic Oxidation of Nitric Oxide: Transient Behavior and Reaction Kinetics. J. Photochem. Photobiol., A 2003, 156, 161-170.

(74) Ao, C. H.; Lee, S. C.; Mak, C. L.; Chan, L. Y. Photodegradation of Volatile Organic Compounds (VOCs) and NO for Indoor Air Purification Using $\mathrm{TiO}_{2}$ : Promotion Versus Inhibition Effect of NO. Appl. Catal., B 2003, 42, 119-129.

(75) Ao, C. H.; Lee, S. C.; Yu, J. C. Photocatalyst $\mathrm{TiO}_{2}$ Supported on Glass Fiber for Indoor Air Purification: Effect of $\mathrm{NO}$ on the Photodegradation of $\mathrm{CO}$ and $\mathrm{NO}_{2}$. J. Photochem. Photobiol., A 2003, 156, 171-177. 